\title{
RENATO VALENTIM
}

Concentrações plasmáticas de progesterona e eficiência reprodutiva de diferentes dispositivos de liberação lenta de progesterona usados em inseminação artificial em tempo fixo

São Paulo 


\title{
RENATO VALENTIM
}

Concentrações plasmáticas de progesterona e eficiência reprodutiva de diferentes dispositivos de liberação lenta de progesterona usados em inseminação artificial em tempo fixo

\author{
Tese apresentada ao Programa de Pós-Graduação em \\ Reprodução Animal da Faculdade de Medicina Veterinária e \\ Zootecnia da Universidade de São Paulo para obtenção do \\ Título de Doutor em Medicina Veterinária \\ Departamento: \\ Reprodução Animal \\ Área de concentração: \\ Reprodução Animal \\ Orientador: \\ Prof. Dr. Renato Campanarut Barnabe
}

São Paulo 
Autorizo a reprodução parcial ou total desta obra, para fins acadêmicos, desde que citada a fonte.

DADOS INTERNACIONAIS DE CATALOGAÇÃO-NA-PUBLICAÇÃO

(Biblioteca da Faculdade de Medicina Veterinária e Zootecnia da Universidade de São Paulo)

T.1413

FMVZ

\section{Valentim, Renato}

Concentrações plasmáticas de progesterona e eficiência reprodutiva de diferentes dispositivos de liberação lenta de progesterona usados em inseminação artificial em tempo fixo / Renato Valentim. - São Paulo : R. Valentim, 2004.

$88 \mathrm{f}$. : il.

Tese (doutorado) - Universidade de São Paulo. Faculdade de Medicina Veterinária e Zootecnia. Departamento de Reprodução Animal, 2004.

Programa de Pós-graduação: Reprodução Animal.

Área de concentração: Reprodução Animal.

Orientador: Prof. Dr. Renato Campanarut Barnabe.

1. Bovinos. 2. Hormônios progestacionais. 3. Dispositivo. 4. Sincronização do cio. I. Título. 


\section{ERRATA}

ITEM

REFERÊNCIAS
Onde se lê

73-88 leia-se

74-89 


\section{FOLHA DE AVALIAÇÃO}

Nome do autor: VALENTIM, Renato

Título: Concentrações plasmáticas de progesterona e eficiência reprodutiva de diferentes dispositivos de liberação lenta de progesterona usados em inseminação artificial em tempo fixo

Tese apresentada ao Programa de Pós-Graduação em Reprodução Animal da Faculdade de Medicina Veterinária e Zootecnia da Universidade de São Paulo para obtenção do Título de Doutor em Medicina Veterinária.

Data:

\section{Banca Examinadora}

Prof. Dr.

Instituição:

Assinatura:

Julgamento:

Prof. Dr.

Instituição:

Assinatura:

Julgamento:

Prof. Dr.

Instituição:

Assinatura:

Julgamento:

Prof. Dr.

Instituição:

Assinatura:

Julgamento:

Prof. Dr.

Instituição:

Assinatura:

Julgamento: 
À Berenice

Aos meus pais

Aos meus irmãos

Ao meu país 


\section{AGRADECIMENTOS}

Ao Prof.Dr.Renato Campanarut Barnabe, pela orientação, carinho e amizade que, muitas vezes, se assemelham aos que um pai dedica a um filho.

Ao Prof.Dr.Pietro Sampaio Baruselli, pela orientação e amizade. Por compartilhar conhecimentos e dúvidas de maneira generosa e honesta.

À Profa.Dra.Valquiria Hyppolito Barnabe, pela orientação e pela convivência sempre alegre e positiva.

Aos amigos da Tecnopec, em especial ao Cássio, à Isabel e ao Felix, por me fornecerem o suporte necessário à realização desta tese.

Aos médicos veterinários Dra.Letícia Pantalena e Pedro Paulo Gusmão, pelo auxílio no trabalho com os animais.

Ao médico veterinário Everton Reis, pelas valiosas sugestões e pelos exames ultrasonográficos.

À Prof.Dra.Carmen Neuza Martins Cortada, pelo auxílio e estímulo.

Ao Departamento de Reprodução Animal da Faculdade de Medicina Veterinária e Zootecnia da Universidade de São Paulo, representado pelo Prof.Dr.José Antonio Visintin e pelo Prof.Dr.Claudio Alvarenga de Oliveira, pela oportunidade.

Aos funcionários do VRA, em especial à Silvia, à Taís e à Harumi - cuja paciência é quase infinita -, pela convivência e auxílio.

Aos colegas do curso de Pós-Graduação em Reprodução Animal, pela solidariedade e alegria que marcaram nosso relacionamento.

Ao colega Nélcio, do curso de Pós-Graduação em Reprodução Animal, pelo desprendimento e pela disponibilidade em auxiliar a todos aqueles que o cercam.

Às funcionárias da Biblioteca da FMVZ-USP - orgulho de nossa faculdade -, em especial à Bibliotecária Claudia Maria Pestana.

À Marieta, pelo auxílio na finalização deste trabalho.

A todos aqueles que, direta ou indiretamente, contribuíram para a realização deste trabalho.

\section{Agradeço de coração}




\section{RESUMO}

VALENTIM, R. Concentrações plasmáticas de progesterona e eficiência reprodutiva de diferentes dispositivos de liberação lenta de progesterona usados em inseminação artificial em tempo fixo. [Plasmatic progesterone concentration and reproductive efficiency of different intravaginal progesterone devices used in timed artificial insemination]. São Paulo, 2004. 89 f. Tese (Doutorado em Medicina Veterinária) - Faculdade de Medicina Veterinária e Zootecnia, Universidade de São Paulo, São Paulo, 2004.

Quatro experimentos foram realizados para avaliar as concentrações plasmáticas de progesterona $\left(\left[\mathrm{P}_{4}\right]\right)$ e as taxas de fertilidade na inseminação artificial em tempo fixo (IATF) após o uso de diferentes dispositivos de liberação lenta de progesterona (DP). No primeiro experimento foram utilizadas 4 novilhas ovariectomizadas. Esses animais receberam 5 diferentes tipos de DP, nos quais se variou a superfície de contato $\left(50 \mathrm{~cm}^{2}\right.$ ou $\left.100 \mathrm{~cm}^{2}\right)$ e a dose de progesterona $(0,5 \mathrm{~g} ; 1,0 \mathrm{~g}$ e $2,0 \mathrm{~g})$ Os dispositivos foram inseridos aos pares durante 7 dias e se estabeleceu um intervalo entre tratamentos de pelo menos 30 dias. Com os dados de $\left[\mathrm{P}_{4}\right] 24$ horas e sete dias após a inserção do DP obtiveram-se as seguintes equações de regressão, respectivamente: $\left[\mathrm{P}_{4}\right]^{24 \mathrm{~h}}=0,238+$ 0,0343 (área) + 0,513(dose); $\left(\mathrm{R}^{2^{3}}=0,94\right)$ e $\left[\mathrm{P}_{4}\right]^{7 d}=0,331+0,0056$ (área) $+0,329$ (dose); $\left(R^{2}=0,71\right)$. No segundo experimento foram comparados dois dos dispositivos testados no primeiro estudo: P50-1,0 (50 $\mathrm{cm}^{2}$ área; $1,0 \mathrm{~g}$ dose $\left.\mathrm{P}_{4}\right)$ e $\mathrm{P} 50-1,5\left(50 \mathrm{~cm}^{2}\right.$ área; $1,5 \mathrm{~g}$ dose $\mathrm{P}_{4}$ ) com dois dispositivos comerciais: CIDR (120 cm área; $1,9 \mathrm{~g} \mathrm{P} \mathrm{P}_{4}$ dose) e DIB $\left(120 \mathrm{~cm}^{2}\right.$ área; $1,0 \mathrm{~g} \mathrm{P}_{4}$ dose). Os dispositivos foram inseridos em 15 novilhas Nelore pré-puberes para avaliação das $\left[\mathrm{P}_{4}\right]$ obtendo-se, após 24 horas de inserção, para CIDR, DIB, P50-1,5 e P50-1,0, respectivamente: $7,7 \pm 2,8^{\mathrm{a}} ; 4,5 \pm 0,75^{\mathrm{b}} ; 5,9 \pm 2,5^{\mathrm{b}}$ e $2,1 \pm 0,5^{\mathrm{c}}$ $\mathrm{ng} / \mathrm{ml}$ e após 8 dias, respectivamente: $3,3 \pm 0,7^{\mathrm{a}} ; 2,6 \pm 2,0^{\mathrm{a}} ; 3,0 \pm 2,4^{\mathrm{a}}$ e $1,1 \pm 0,27^{\mathrm{b}} \mathrm{ng} / \mathrm{ml}$. As regressões obtidas no primeiro experimento não foram eficientes para estimar as $\left[\mathrm{P}_{4}\right]$ obtidas no estudo 2. Nos experimentos 3 e 4 comparou-se a eficiência dos dispositivos DIB e P50-1,5 em 431 vacas de corte zebuínas e cruzadas, com bezerros ao pé e multíparas, após uso em um programa de IATF no qual os dispositivos permaneciam nos animais durante 8 dias; quando da colocação desses dispositivos, eram aplicados $2 \mathrm{mg}$ de benzoato de estradiol (BE) e, na retirada, 400UI de eCG. Uma última dose de BE foi administrada 24 horas após a retirada dos DP, e a IATF foi realizada 54 horas após a retirada dos DP. Não foram encontradas diferenças nas taxas de concepção da IATF entre dispositivos. As taxas de concepção variaram entre 30 e $51,6 \%$ nos lotes tratados. O tratamento diminuiu o intervalo tratamento-parto de 365 para 317 dias, comparado à monta natural.

Unitermos: Bovinos. Progesterona. Dispositivo. Sincronização 


\begin{abstract}
VALENTIM, R. Plasmatic progesterone concentration and reproductive efficiency of different intravaginal progesterone devices used in timed artificial insemination [Concentrações plasmáticas de progesterona e eficiência reprodutiva de diferentes dispositivos de liberação lenta de progesterona usados em inseminação artificial em tempo fixo]. São Paulo, 2004. 89 f. Tese (Doutorado em Medicina Veterinária) Faculdade de Medicina Veterinária e Zootecnia, Universidade de São Paulo, 2004.
\end{abstract}

Four studies have been made to evaluate the plasmatic progesterone concentration $\left(\left[P_{4}\right]\right)$ of different intravaginal low delivery progesterone devices (PD) and the fertility rates after their use in timed artificial insemination (TAI). In the first study there were used 4 ovariectomized heifers. These animals received 5 kinds of prototypes PD on which varied the contact surface (50 or $\left.100 \mathrm{~cm}^{2}\right)$ and the progesterone doses $(0,5 ; 1,0$ or $2 \mathrm{~g}$ ). These PD were inserted in the vaginas in pairs and the interval between treatments was higher than 30 days. With the data of $\left[\mathrm{P}_{4}\right]$ there were found the fallowing regressive equations for the days 1 and 7 after the insertion, respectively: $\left[P_{4}\right]^{24 h}=$ $0,238+0,0343$ (surface) $+0,513$ (dose); $\left(R^{2}=0,94\right)$ and $\left[P_{4}\right]^{7 d}=0,331+0,0056$ (surface) + 0,329 (dose); $\left(R^{2}=0,71\right)$. In the second study there were compared 2 prototypes $P D$ based on the first study: P50-1,0 $\left(50 \mathrm{~cm}^{2}\right.$ surface; $1,0 \mathrm{~g}$ dose $\left.\mathrm{P}_{4}\right)$ and P50-1,5 $\left(50 \mathrm{~cm}^{2}\right.$ surface; $1,5 \mathrm{~g}$ dose $\left.\mathrm{P}_{4}\right)$ with two commercial PD: CIDR $\left(120 \mathrm{~cm}^{2}\right.$ surface; $1,9 \mathrm{~g} \mathrm{P} \mathrm{P}_{4}$ dose $)$ and DIB (120 $\mathrm{cm}^{2}$ surface; $1,0 \mathrm{~g} \mathrm{P}_{4}$ dose). These PD were inserted in 15 prepuberal Nelore heifers to evaluate the $\left[\mathrm{P}_{4}\right]$ The $\left[\mathrm{P}_{4}\right]$ (in $\mathrm{ng} / \mathrm{ml}$ ) found after 24 hours were for CIDR, DIB, P50-1,5 e P50-1,0, respectively: $7.7 \pm 2.8^{\mathrm{a}} ; 4.5 \pm 0.75^{\mathrm{b}} ; 5.9 \pm 2.5^{\mathrm{b}}$ e $2.1 \pm 0.5^{\mathrm{c}}$ $\mathrm{ng} / \mathrm{ml}$ and after 8 days, respectively: $3.3 \pm 0.7^{\mathrm{a}} ; 2.6 \pm 2.0^{\mathrm{a}} ; 3.0 \pm 2.4^{\mathrm{a}}$ e $1.1 \pm 0.27^{\mathrm{b}} \mathrm{ng} / \mathrm{ml}$. The regressive equations found in the first study were not efficient to estimate the $\left[\mathrm{P}_{4}\right]$ for the prototypes PDs. In the studies 3 and 4 there were compared the PD DIB and P50-1.5 for TAI in 431 Nelore and cross-breed lactating postpartum beef cows. The TAI protocol was: PD insertion per 8 days, administration of $2 \mathrm{mg}$ estradiol benzoate $(\mathrm{EB})$ in the insertion day - $400 \mathrm{UI}$ of eCG in the PD removal - 1mg EB 24 hours after PD removalTAI 54 hours after the PD removal. There were no differences in TAl conception rates between PD. The TAl conception rates ranged from 30 to $51.6 \%$ in the treated herds. The treatment has decreased the treatment-partum interval from 365 to 317 days on animals submitted to natural mating.

Key words: Cow. Progesterone. Device. Synchronization. 


\section{LISTA DE TABELAS}

Tabela 1 Médias de peso, escore de condição corporal e intervalo pós-parto de três lotes de animais submetidos à IATF. Campo Grande, 2004 .

Tabela 2 Estimativas de concentrações plasmáticas de progesterona em $\mathrm{ng} / \mathrm{ml}$ em função da área de superfície de contato e da dose de progesterona em dispositivos após 24 horas de inserção. São Paulo, 2002

Tabela 3 Estimativas de concentrações plasmáticas de progesterona em $\mathrm{ng} / \mathrm{ml}$ em função da área de superfície de contato e dose de progesterona em dispositivos após sete dias de inserção. São Paulo, 2002

Tabela 4 Progesterona plasmática de novilhas após inserção de diferentes dispositivos de progesterona. Cornélio Procópio, 2002

Tabela 5 Taxas de prenhez da IATF(TP-IATF), taxas de retorno da IATF (TR-IATF), taxas de concepção da IA convencional (TC-IA), taxas de prenhez da IATF + IA convencional (TP-IA+IATF), taxas de prenhez no final da estação reprodutiva de 90 dias (TP-final) e intervalo tratamento-parto (ITP) de vacas sob programa IATF com dois tipos de dispositivos de liberação lenta de progesterona ou cobertas por touros. Gurupi, 2003

Tabela 6 Taxas de prenhez após a IATF(TP-IATF), taxas de retorno da IATF (TR-IATF), taxas de concepção da IA convencional (TC-IA), taxas de prenhez da IATF + IA convencional (TP-IA+IATF), taxas de prenhez no final da estação reprodutiva de 100 dias (TP-final) e intervalo tratamento-parto (ITP) de vacas em função do escore de condição corporal (1 a 9). Gurupi, 2003

Tabela 7 Taxas de prenhez da IATF de vacas Nelore com dois tipos de dispositivos de progesterona. Campo Grande, 2004

Tabela 8 Taxas de prenhez da IATF de vacas Nelore em função da classificação ovariana. Campo Grande, 2004

Tabela 9 Taxas de prenhez da IATF de vacas Nelore em função da seqüência de inseminação. Campo Grande, 2004 


\section{LISTA DE FIGURAS}

Figura 1 Protocolos experimentais

Figura 2 Protocolos experimentais

Figura 3 Concentrações plasmáticas de progesterona durante 8 dias de inserção de 5 diferentes tipos de dispositivos vaginais de liberação lenta de progesterona. Cornélio Procópio, 2002 


\section{SUMÁRIO}

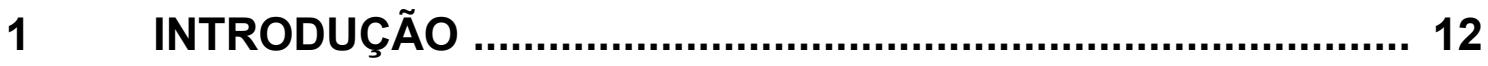

2 REVISÃO DA LITERATURA .............................................. 15

2.1 FOLICULOGÊNES E CONTROLE DA DINÂMICA FOLICULAR ..... 15

2.1.1 ONDAS DE CRESCIMENTO E DOMINÂNCIA FOLICULAR .............................. 15

2.1.1.1 Hormônio Folículo Estimulante (FSH) ……............................... 18

2.1.1.2 Hormônio Luteinizante (LH) .................................................. 19

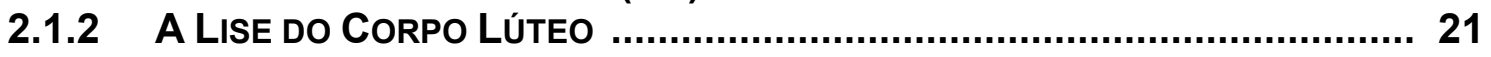

2.2 FOLICULOGÊNESE EM Bos indicus ......................................... 21

2.3 SINCRONIZAÇÃO DO ESTRO E CONTROLE DA EMERGÊNCIA FOLICULAR E DA OVULAÇÃO …............................................ 23

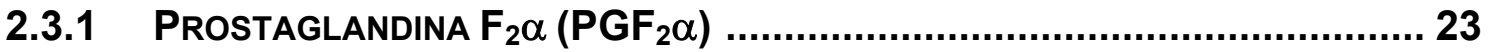

2.3.2 PROGESTERONA E PROGESTÁGENOS ............................................... 25

2.4 INSEMINAÇÃO ARTIFICIAL EM TEMPO FIXO (IATF) COM DISPOSITIVOS DE LIBERAÇÃO LENTA DE PROGESTERONA ... 28

2.4.1 FATORES QUE INTERFEREM NOS RESULTADOS DE PRENHEZ ...................... 28

2.4.2 EFEITO do ANESTRO NA INSEMINAÇÃo ARTIFICIAL EM TEMPO FIXO ........... 30

2.5 DISPOSITIVOS INTRAVAGINAIS DE LIBERAÇÃO LENTA DE

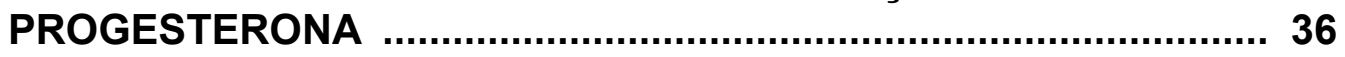

3 MATERIAL E MÉTODO ....................................................... 40

3.1 EXPERIMENTO 1 - EFEITO DA ÁREA DE SUPERFÍCIE DE CONTATO E DA DOSE DE PROGESTERONA DO DISPOSITIVO NA CONCENTRAÇÃO PLASMÁTICA

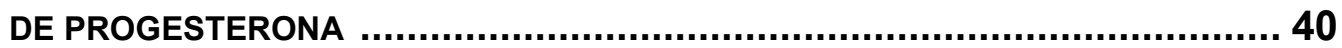

3.1.1 ANIMAIS E LOCAL DO EXPERIMENTO ............................................... 40

3.1.2 TRATAMENTOS ........................................................................... 40

3.1.3 COLETA DE MATERIAL .................................................................... 41

3.1.4 DOSAGEM DAS CONCENTRAÇÕES PLASMÁTICAS DE PROGESTERONA ........ 42

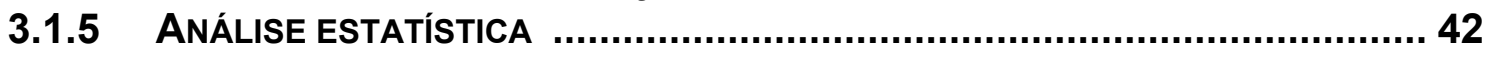

3.2 EXPERIMENTO 2- EFEITO DE DIFERENTES DISPOSITIVOS DE PROGESTERONA SOBRE AS CONCENTRAÇÕES PLASMÁTICAS DE PROGESTERONA DURANTE 8 DIAS ................................................. 42

3.2.1 ANIMAIS E LOCAL DO EXPERIMENTO .............................................. 42

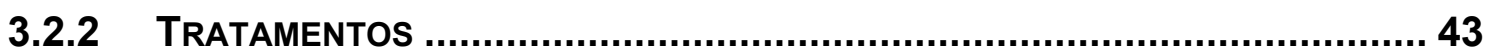

3.2.3 COLETA DE MATERIAL ….......................................................... 44

3.2.4 DOSAGEM DAS CONCENTRAÇÕES PLASMÁTICAS DE PROGESTERONA .........44

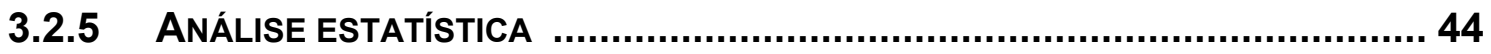

3.3 EXPERIMENTO 3 - TAXA DE CONCEPÇÃO DA INSEMINAÇÃO ARTIFICIAL EM TEMPO FIXO (IATF) EM VACAS NELORE E CRUZADAS TRATADAS COM DOIS DIFERENTES DISPOSITIVOS COMPARADOS COM MONTA NATURAL, EM ESTAÇÃO REPRODUTIVA DE 90 DIAS .................................................45

3.3.1 ANIMAIS E LOCAL DO EXPERIMENTO …............................................... 45

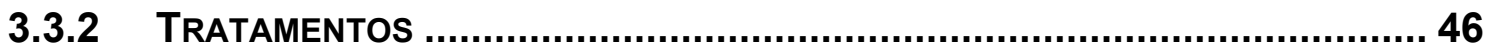

3.3.3 FERTILIDADE DO SÊMEN E DOS TOUROS ............................................. 48

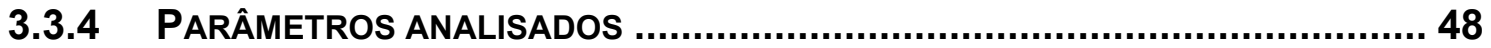

3.3.4.1 Avaliação dos parâmetros .................................................... 49

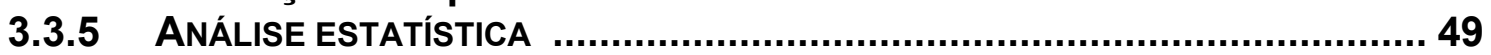


3.4 EXPERIMENTO 4 - RESULTADOS DA INSEMINAÇÃo ARTIFICIAL EM TEMPO FIXO (IATF) EM VACAS NELORE COMPARANDO DOIS TIPOS DE DISPOSITIVOS DE LIBERAÇÃO DE PROGESTERONA ................................. 50

3.4.1 ANIMAIS E LOCAL DO EXPERIMENTO .................................................. 50

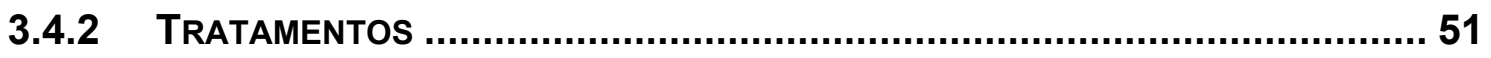

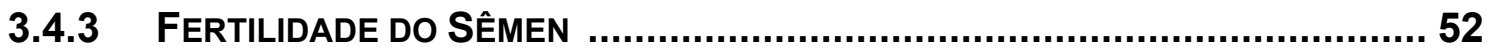

3.4.4 PARÂMETROS ANALISADOS ............................................................. 53

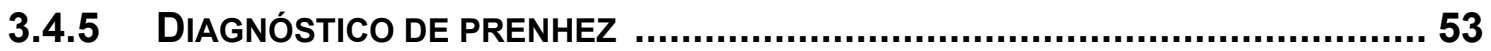

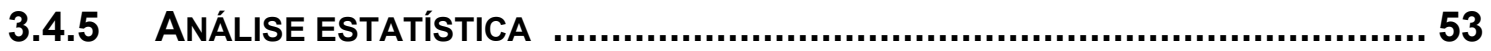

$4 \quad$ RESULTADOS E DISCUSSÃO ............................................ 54

4.1 EXPERIMENTO 1 - EFEITO DA ÁREA DE SUPERFÍCIE DE CONTATO E DA DOSE DE PROGESTERONA DO DISPOSITIVO NA CONCENTRAÇÃO

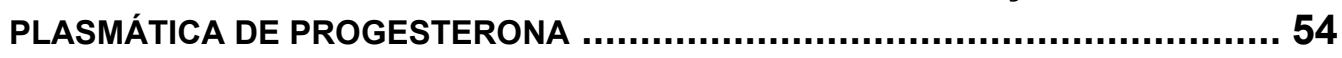

4.2 EXPERIMENTO 2- EFEITO DE DIFERENTES DISPOSITIVOS DE PROGESTERONA SOBRE AS CONCENTRAÇÕES PLASMÁTICAS DE PROGESTERONA DURANTE 8 DIAS 57

4.3 EXPERIMENTO 3 - TAXA DE CONCEPÇÃO DA INSEMINAÇÃO ARTIFICIAL EM TEMPO FIXO (IATF) EM VACAS NELORE E CRUZADAS TRATADAS COM DOIS DIFERENTES DISPOSITIVOS COMPARADOS COM MONTA NATURAL, EM ESTAÇÃO REPRODUTIVA DE 90 DIAS

4.4 EXPERIMENTO 4 - RESULTADOS DA INSEMINAÇÃo ARTIFICIAL EM TEMPO FIXO (IATF) EM VACAS NELORE COMPARANDO DOIS TIPOS DE DISPOSITIVOS DE LIBERAÇÃO DE PROGESTERONA ...................................................67 67

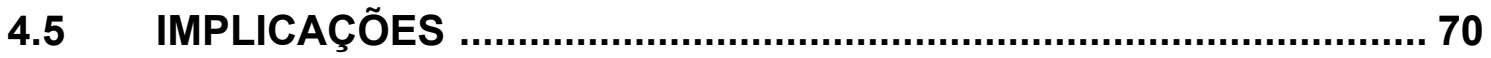

$5 \quad$ CONCLUSÕES ..................................................................... 73

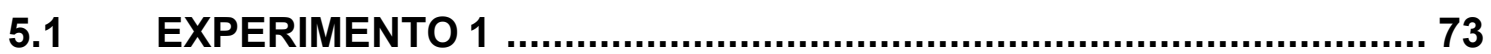

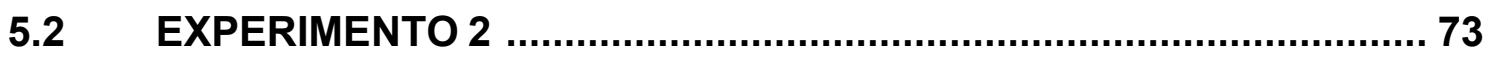

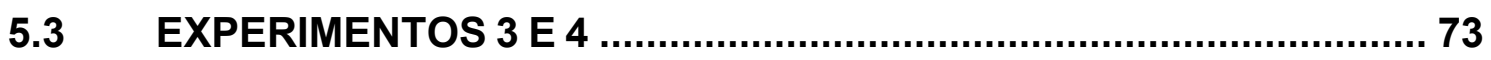

REFERÊNCIAS ................................................................. 74 


\section{INTRODUÇÃO}

Dados oficiais (INSTITUTO BRASILEIRO DE GEOGRAFIA E ESTATÍSTICA - IBGE -, 2002) sobre a participação de cada setor econômico no Produto Interno Bruto (PIB) brasileiro mostram que a agropecuária tem sustentado em grande parte o crescimento do país. O enorme patrimônio representado pelos rebanhos brasileiros e pelos setores a eles vinculados mais que justifica os investimentos em pesquisas de novas tecnologias que possibilitem o aumento da produção nessa área.

Por multiplicar os animais de melhor desempenho, o melhoramento genético possibilita o incremento da produtividade na bovinocultura de corte. A utilização de reprodutores provados - testes de progênie ou de desempenho - elimina os fatores aleatórios decorrentes da escolha de touros pela ascendência, pelos resultados de pista ou por porte/tipo e possibilita, ao produtor, estimar o ganho genético e o custo beneficio do uso de um determinado touro em função de seu Desvio Esperado de Progênie (DEP).

Entretanto, a propagação desse tipo de material genético esbarra na baixa utilização da inseminação artificial no Brasil. Segundo a Associação Brasileira de Inseminação Artificial (ASBIA, 2002), apenas 5\% das vacas do rebanho nacional são inseminadas, percentual bastante pequeno frente à importância dessa técnica mas que também configura um grande potencial para o melhoramento do gado e uma ótima oportunidade de mercado. 
Um dos principais fatores que determinam o resultado de programas de inseminação artificial é a eficiência na detecção de cios. As falhas de observação de cio foram mensuradas por vários autores, variando entre 27\% e 45\% (CAVALIERI; FITZPATRICK, 1995; STEVENSON et al., 1996). A eficiência de detecção de cios é influenciada, dentre outros aspectos, pela qualificação da mão-de-obra e pela alta incidência de cios e montas noturnas (FÊO; BARNABE, 1980; PINHEIRO et al.,1998; STEVENSON et al., 1996), pela curta duração de cios de animais zebuínos e cruzados e pela baixa intensidade do cio em zebuínos (GALINA; ARTUR, 1990; LAMOTHE-ZAVALETA; FREDRIKSSON; KINDAHL, 1991; RANDEL, 1984) e por fatores ambientais (LAMOTHE-ZAVALETA; FREDRIKSSON; KINDAHL, 1991). Também a alta porcentagem de animais em anestro tem prejudicado os programas de inseminação artificial e limitado o uso dessa biotécnica.

Estudos recentes sobre a fisiologia do ciclo estral de bovinos permitiram o desenvolvimento de modernos protocolos de inseminação artificial sem observação de cios. Essa nova tecnologia tem sido hábil para solucionar os problemas inerentes à inseminação artificial convencional - baseada na observação de cios -, mas seu custo ainda é elevado, principalmente por causa dos dispositivos de liberação lenta de progesterona, essenciais aos protocolos.

Os dispositivos de liberação lenta de progesterona atualmente disponíveis no mercado são compostos por uma alma plástica rígida, revestida por uma membrana de elastômero de silicone inerte impregnada por progesterona. Em estudo comercial sobre a fabricação desses dispositivos ${ }^{1}$, constatou-se que os custos correspondentes às frações alma plástica, membrana de silicone e progesterona representam, respectivamente, $10 \%$; $64 \%$ e $26 \%$, o que significa que a

General Electric S/A (2001). 
queda do valor desse tipo de produto está relacionada primeiramente à diminuição da quantidade de silicone utilizada e do tempo de processamento deste e, em segundo lugar, à diminuição da dose de progesterona. Assim, novas investigações para o desenvolvimento de dispositivos de baixo custo se fazem necessárias.

Desta forma, os objetivos do presente trabalho foram:

EXPERIMENTO 1: Estabelecer a relação entre a superfície de contato e a dose de progesterona do dispositivo sobre a concentração plasmática de progesterona, utilizando cinco protótipos de dispositivos de liberação lenta desse hormônio.

EXPERIMENTO 2: Comparar dois protótipos selecionados no experimento $1 \mathrm{com}$ dois tipos de dispositivos comerciais, para avaliar as concentrações iniciais e finais de progesterona plasmática e a queda diária da concentração de progesterona plasmática durante oito dias. Testar as equações de regressão obtidas no experimento 1.

EXPERIMENTO 3:Testar, a campo, a eficiência de um dos protótipos avaliados no experimento 2, comparando os resultados de prenhez por ele obtidos e aqueles promovidos por um dispositivo comercial e pela monta natural.

EXPERIMENTO 4:Testar, a campo, a eficiência de um dos protótipos avaliados no experimento 2, comparando os resultados de prenhez por ele obtidos e aqueles promovidos por um dispositivo comercial, em condições ambientais diferentes daquelas do experimento 3 . 


\section{REVISÃO DA LITERATURA}

\subsection{FOLICULOGÊNESE E CONTROLE DA DINÂMICA FOLICULAR}

\subsubsection{ONDAS DE CRESCIMENTO E DOMINÂNCIA FOLICULAR}

O primeiro estudioso a formular a hipótese de crescimento folicular em ondas foi Rajakosk (1960), após analisar histologicamente ovários de novilhas abatidas em todos os dias do ciclo estral. Embora posteriormente essa hipótese tenha sido parcialmente confirmada por Dufour et al. (1972); Matton et al. (1981), sua aceitação final só ocorreu depois dos primeiros trabalhos de controle de desenvolvimento folicular por ultra-sonografia. Pierson e Ginther (1984) foram os primeiros a monitorar o diâmetro dos folículos durante o ciclo de novilhas, descrevendo o crescimento de um folículo até o tamanho ovulatório, e sua regressão aproximadamente no meio do ciclo. Também acompanharam o crescimento acelerado de um folículo ovulatório dias antes da ovulação e a regressão daqueles não destinados à ovulação. Em trabalho posterior, os mesmos autores (PIERSON; GINTHER, 1987a, b) mostraram mais detalhadamente tais eventos. Para Ginther, Knopf e Kastelic (1989), a duração do ciclo estral está associada ao número de ondas foliculares; nesse trabalho, novilhas européias com duas e três ondas apresentaram ciclos de $20,4 \pm 0,3$ e $22,8 \pm 0,6$ dias, respectivamente.

A teoria da dominância folicular foi formulada por Goodman et al. (1977) para explicar o reduzido crescimento dos folículos na presença de um folículo 
ovulatório de primatas. Entretanto, somente em 1987, com a utilização da ultrasonografia, Ireland (1987); Ireland et al. (2000) descreveram a dominância folicular em bovinos. Esses autores postulam que um único folículo estrógeno-ativo torna-se dominante, o que ocorre três vezes durante o ciclo. Também observaram a elevação das concentrações plasmáticas de estradiol associada ao aumento do tamanho dos folículos e às concentrações intrafoliculares de estradiol. Assim, concluíram que três ciclos de desenvolvimento dos folículos dominantes ocorrem durante o ciclo estral bovino. Cada ciclo de desenvolvimento do folículo dominante passa por fases de seleção, dominância e atresia ou ovulação. Quatro importantes trabalhos posteriores confirmaram esse postulado e estabeleceram os padrões de desenvolvimento folicular (FORTUNE; SIROIS; QUIRK, 1988; PIERSON; GINTHER, 1988; SAVIO et al., 1988; SIROIS; FORTUNE, 1988). Em revisão publicada em 2000, Ireland et al. analisaram os dados desses trabalhos e relataram que, dos 46 ciclos de novilhas controlados por ultra-sonografia, um ciclo foi de uma onda folicular, oito ciclos foram de duas ondas, 35 ciclos foram de três ondas e dois ciclos foram de quatro ondas, concluindo que os ciclos de três ondas são os mais comuns em novilhas. Vários dados importantes foram descritos nos quatro estudos pioneiros anteriormente citados: o início da onda, também chamado de emergência, foi definido como o dia do ciclo estral em que se pode detectar, por ultra-sonografia, o primeiro folículo de uma nova onda folicular; os dias da emergência das ondas foliculares variam em função do número de ondas do ciclo; em novilhas de três ciclos, as ondas têm início, em média, nos dias 1,9 (amplitude de 1 a 3); 9,4 (8 a 11) e 16,1 (14 a 19); para a primeira, segunda e terceira ondas, o tamanho máximo dos folículos dominantes foi de 12,3 a $15,5 \mathrm{~mm}, 10,2$ a 15,9mm e 12,8 a 18,8mm, respectivamente; a duração de um folículo não ovulatório foi de 11,4 a 17 dias na primeira onda, e de 7,4 a 13,1 
dias na segunda onda, enquanto a duração do folículo da terceira onda foi de 6 dias antes da ovulação; o diâmetro máximo de um folículo não dominante foi de $8 \mathrm{~mm}$. Tais autores (FORTUNE; SIROIS, QUIRK, 1988; PIERSON; GINTHER, 1988; SAVIO et al., 1988; SIROIS; FORTUNE, 1988) utilizaram o conceito de "recrutamento" descrito para primatas por Goodman e Hodgen (1983), definindo-o como o processo pelo qual os folículos primordiais iniciam uma fase de crescimento dependente de gonadotrofinas: hormônio folículo estimulante (FSH) e hormônio luteinizante (LH).

Com base em acompanhamento ultra-sonográfico, Ginther, Kastelic e Knopf (1989) observaram que os folículos dominantes crescem até uma fase estática, seguida por uma fase de regressão. Tais períodos, especialmente a fase de regressão, estendem-se sobre a próxima onda. A fase de crescimento, portanto, é o período em que se constata a emergência de uma nova onda até o momento em que o diâmetro do folículo cessa de aumentar. A fase estática compreende o período em que o folículo não altera seu diâmetro, e termina no dia anterior ao início da fase de regressão, na qual o folículo perde seu diâmetro até não ser mais detectado. A divergência, aumento rápido da diferença dos diâmetros entre o folículo dominante e os dominados, marca o final da fase de seleção, define a primeira mudança funcional e permite diagnosticar a dominância de um folículo. Sirois e Fortune (1990) definiram o folículo dominante como aquele cuja estrutura supera em $2 \mathrm{~mm}$ os demais folículos. Bao et al. (1997) observaram que a seleção do folículo dominante ocorre entre 36 e 48 horas após o início da onda folicular. O primeiro folículo que adquire receptores para LH nas células da granulosa torna-se dominante, adquirindo a capacidade de responder a ambas as gonadotrofinas (BAO; GARVERICK, 1998). 


\subsubsection{Hormônio Folículo Estimulante (FSH)}

O uso do ultra-som permitiu a vários pesquisadores associar os padrões de liberação das gonadotrofinas à dinâmica folicular. Turzillo e Fortune (1990) demonstraram que o aumento de FSH após a ovulação precede a primeira onda de desenvolvimento folicular. Adams, Evans e Rawlings (1992) acrescentaram que um aumento significativo de FSH precede cada nova onda de desenvolvimento folicular, ocorrendo em média um dia antes de sua emergência. Em animais de três ondas, os picos ocorriam, aproximadamente, nos dias 1, 9 e 15 do ciclo estral. Os estudos anteriores foram confirmados por Cooke, Crowe e Roche (1997); Fortune (1994); Sunderland et al. (1994). Posteriormente, constatou-se que esses padrões de liberação de $\mathrm{FSH}$ associados à emergência de uma nova onda também ocorrem em animais pré-púberes (ADAMS et al., 1994; EVANS et al., 1997), durante a prenhez (GINTHER et al., 1996a; TAYLOR; RAJAMAHENDRAM, 1991) e durante o anestro pós-parto (CROWE et al., 1998; ROCHE; CROWE; BOLAND, 1992).

O controle hormonal do desenvolvimento folicular foi mais profundamente estudado por Turzillo e Fortune (1990), que conseguiram suprimir o pico de FSH e impedir o desenvolvimento de uma nova onda folicular após a injeção de fluido folicular em novilhas, e por Adams et al. (1993), que trataram novilhas com FSH no momento da queda espontânea dessa gonadotrofina, induzindo o atraso do início da dominância. Os resultados de tais investigações indicam que o FSH é essencial no início do crescimento folicular, e que sua diminuição define o final do processo de seleção. Trabalhos mais recentes, ainda que não tenham desvendado o mecanismo do recrutamento, apontam que o desenvolvimento folicular pré-antral independe de 
gonadotrofinas, e que mecanismos parácrinos de controle são hegemônicos nessa fase (GONG et al., 1996; MONNIAUX et al., 1997a, b).

O folículo dominante se caracteriza pelo aumento da produção de estrógeno e por alterações na proporção estrógeno/progesterona intrafolicular (SUNDERLAND et al., 1994). Fortune (1994); Ireland et al. (1994) relataram que a dominância folicular é regulada por estrógeno e inibina produzidos pelo folículo dominante. Tais hormônios, por um mecanismo de retroalimentação negativa sobre o eixo hipotálamo-hipofisário, provocam a redução das concentrações plasmáticas de FSH e bloqueiam o crescimento dos folículos menores - mais dependentes dessa gonadotrofina -, induzindo-os à atresia (PRICE, 1991). A inibina parece ser secretada por todos os folículos maiores que $3 \mathrm{~mm}$, enquanto as concentrações de estradiol aumentam com o crescimento do folículo dominante (WILTBANK et al., 1996). O folículo dominante, por sua vez, tem seu crescimento limitado pela progesterona $\left(\mathrm{P}_{4}\right)$, e só se tornará um folículo ovulatório se houver regressão do corpo lúteo e um pico de LH (GINTHER; KASTELIC; KNOPF, 1989; LUCY et al., 1992).

\subsubsection{Hormônio Luteinizante (LH)}

Após trabalharem com novilhas canuladas, Rahe et al. (1980) revelaram que os padrões de secreção de LH mudam: no início da fase luteal, apresentam alta freqüência e baixa amplitude; no meio da fase luteal, têm baixa freqüência e alta amplitude; e, durante o estro, apresentam alta freqüência e alta amplitude. Roberson et al. (1989) mostraram que o tratamento com progesterona determina uma retroalimentação negativa sobre o eixo hipotálamo-hipofisário, reduzindo a 
freqüência de liberação e as concentrações séricas de LH. O papel dos padrões de liberação do LH sobre o folículo dominante foi avaliado por Savio et al. (1993); Stock e Fortune (1993), que avaliaram a liberação de LH após a queda da progesterona ou após suplementação com dispositivos de liberação lenta desse hormônio. Os resultados de tais investigações mostraram que baixas concentrações séricas de progesterona estão associadas à alta freqüência de pulsos de LH - tipo de liberação necessário para a manutenção da dominância -, ao passo que altas concentrações de progesterona reduzem a freqüência de pulsos de $L H$, induzindo a perda de dominância e o início de uma nova onda folicular.

$\mathrm{Na}$ divergência, o crescimento acentuado do folículo dominante está relacionado à formação de receptores de $\mathrm{LH}$, o que permite a manutenção de seu crescimento e de sua maturação folicular. Graças à deficiência desses receptores, e também em conseqüência da diminuição do FSH promovida pela liberação de estrógenos e inibina pelo folículo dominante, os folículos subordinados acabam sofrendo atresia (GINTHER et al., 1996b)

O crescimento do folículo dominante eleva as concentrações de estrógenos que, na ausência de progesterona, promovem uma retroalimentação positiva para a secreção de GnRH no hipotálamo e um conseqüente pico de LH (VOSS; FORTUNE, 1993a, b), promovendo a ovulação e a luteinização das células da granulosa e dando origem a um novo corpo lúteo (MILVAE; HINCKLEY; CARLSON, 1996). Desta forma, a condição essencial para que ocorra a ovulação é a diminuição das concentrações de progesterona. 


\subsubsection{A LISE DO CORPO LÚTEO}

A lise do corpo lúteo é induzida pela prostaglandina $\mathrm{F}_{2 \alpha}-\mathrm{PGF}_{2 \alpha}-(\mathrm{HORTON}$; POYSER, 1975; ROWSON; TERVIT; BRAND, 1972). De acordo com Thatcher et al. (2001), a interação entre as células do trofoectoderma do concepto e as células do endométrio é fundamental para a manutenção do corpo lúteo. O Interferon- $\tau$ é o sinal do embrião para que o endométrio não produza a PGF Pa (WATHES et al., 1998), atuando no bloqueio dos receptores de ocitocina das células endometriais. O mecanismo de ação da ocitocina ainda não é totalmente conhecido. A ocitocina, proveniente do corpo lúteo ou da neuro-hipófise, estimula a secreção de PGF $_{2 \alpha}$ após estimular receptores endometriais próprios (FUCHS et al., 1990). Sua liberação no corpo lúteo, no qual - além da neuro-hipófise - é produzida (FILDS; DUBOIS; FIELDS, 1985) também é estimulada pela própria PGF $2 a$ (FLINT; SHELDRICK, 1982), o que parece gerar um mecanismo de retroalimentação positiva que culmina com níveis de $\mathrm{PGF}_{2 \alpha}$ suficientemente elevados para a lise do corpo lúteo.

\subsection{FOLICULOGÊNESE EM Bos indicus}

O desenvolvimento folicular em Bos indicus também ocorre em ondas, normalmente duas ou três por ciclo estral (FIGUEIREDO et al., 1997; RHODES; DEATH; ENTWISTLE, 1995), e de maneira bastante semelhante ao padrão anteriormente descrito para o Bos taurus. Barros, Figueiredo e Pinheiro (1995); Figueiredo et al. (1997) comentam que, em fêmeas Nelore, os ciclos são predominantemente de três ondas em novilhas (67\%) e de duas ondas em vacas (90\%). Nas raças Gir e Girolanda observou-se a predominância de três ondas 
foliculares, tanto em novilhas quanto em vacas (CASTILHO et al., 1996; GAMBINI et al., 1997). A duração do ciclo estral dos zebuínos também está associada ao número de ondas foliculares. Vacas de duas e três ondas apresentaram ciclos de $18,7 \pm 0,4$ e 20,9 $\pm 0,5$ dias, respectivamente (ALVAREZ et al., 2000).

Os folículos e os corpos lúteos dos zebuínos apresentaram, respectivamente, as seguintes medidas de diâmetro máximo: 10 a 12mm e 17 a 21mm (BARROS et al., 1993; BÓ et al., 1993a, b; FIGUEIREDO et al., 1997; RHODES; DEATH; ENTWISTLE, 1995) menores, portanto, que as medidas dessas estruturas em taurinos: 14 a 20mm e 20 a 30mm, respectivamente (BÓ et al., 1993b; GINTHER; KASTELIC; KNOPF, 1989; KASTELIC; KO; GINTHER, 1990). No que concerne às populações foliculares, foi observado maior número de folículos menores que $5 \mathrm{~mm}$ e menor número de folículos maiores que $5 \mathrm{~mm}$ em novilhas Bos indicus do que em novilhas Bos taurus (SEGERSON et al., 1984).

Também há registros de diferenças endocrinológicas entre zebuínos e taurinos. Os resultados de dosagens hormonais em zebuínos indicam que estes apresentam menores concentrações séricas de LH (D’OCCHIO; NEISH; BROADHURST, 1990; RANDEL, 1976; RHODES III; RANDEL; HARMS, 978) e menores níveis de estradiol e progesterona que os animais de raças européias (RANDEL, 1984; SEGERSON et al., 1984). O intervalo entre o pico de estrógeno ou aplicação de estrógeno - e a liberação de LH é, segundo Rhodes III, Randel e Harms (1978), mais curto para zebuínos do que para taurinos. Também Randel (1976) relata que fêmeas zebuínas (Brahman) ovularam, após a liberação do LH, em menor intervalo de tempo que fêmeas taurinas e cruzadas $(18,5 \pm 3,1 \mathrm{~h}$ vs. $23,3 \pm 2,1 \mathrm{~h}$ vs. $22,2 \pm 2,6 \mathrm{~h}$, respectivamente). Entretanto, em estudos mais recentes nos quais foram utilizadas técnicas mais acuradas para o diagnóstico da ovulação - ultra-som -, 
os intervalos entre a liberação de LH e a ovulação em zebuínos foram de $23,3 \pm 2,2 \mathrm{~h}$ (ALONSO et al., 1995) e de 25,9 $\pm 0,6 \mathrm{~h}$ (CAVALIERI et al., 1997).

\subsection{SINCRONIZAÇÃO DO ESTRO E CONTROLE DA EMERGÊNCIA FOLICULAR E DA OVULAÇÃO}

\subsubsection{Prostaglandina $F_{2} \alpha\left(\right.$ PGF $\left._{2} \alpha\right)$}

A partir da comprovação dos efeitos luteolíticos da $\mathrm{PGF}_{2} \alpha$ em bovinos (ROWSON; TERVIT, BRAND, 1972), vários análogos dessa molécula foram sintetizados e considerados efetivos na indução da lise do corpo lúteo e na sincronização de cios em bovinos (INSKEEP, 1973; LARSON; BALL, 1992; ODDE, 1990; THATCHER; CHENAULT, 1976). A prostaglandina $F_{2} \alpha$ e seus análogos se mostraram ineficientes na ausência de um corpo lúteo (KIRACOFE; KEAY; ODDE, 1985; ROWSON; TERVIT; BRAND, 1972). O corpo lúteo recém formado não é lisado por esses compostos; essa lise começa a ocorrer com baixa eficiência após o $5^{\circ}$ dia do cio e, mais eficientemente, após o $7^{\circ}$ dia (ODDE, 1990). Isso significa que a aplicação de uma única dose desses produtos em um rebanho cujos animais estejam ciclando provoca luteólise em, no máximo, $70 \%$ das fêmeas. Assim, para a utilização de uma dose única é necessário identificar previamente a presença do corpo lúteo; também pode ser administrada dose dupla com intervalo de 11 a 14 dias, pois melhores índices de sincronização do cio ocorrem após a segunda dose (CHENAULT, 1992; LAUDERDALE et al., 1981; ODDE, 1990).

Uma das limitações da $\mathrm{PGF}_{2} \alpha$ é a alta variação no intervalo entre o tratamento e a manifestação de cio (TANABE; HANN, 1984), o que impede a 
utilização de protocolos de inseminação em tempo fixo (IATF). O intervalo entre a aplicação da $\mathrm{PGF}_{2} \alpha$ e a manifestação do estro varia em função do estágio de desenvolvimento dos folículos; assim, animais no início da onda de crescimento folicular manifestariam o cio cerca de seis dias após a aplicação, enquanto animais com folículos dominantes na fase de crescimento terminal ou na fase estática entrariam em cio entre 48 e 60 horas após o tratamento (KASTELIC; GINTHER, 1991).

A eficiência da sincronização de cios com $\mathrm{PGF}_{2} \alpha$ e seus análogos varia em função da raça. Altas taxas de cios foram relatadas em animais europeus (66 a 97\% por LAVERDIERE et al., 1995, e 70 a 90\% por TANABE; HANN, 1984). Entretanto, em zebuínos os resultados têm se mostrado mais variáveis. Em vacas das raças Nelore (CASTILHO; DAYAN; BARROS, 1997; FIGUEIREDO et al., 1997) e Gir (GAMBINI et al., 1997) foi observada baixa manifestação de estro (<50\%) após tratamentos com $\mathrm{PGF}_{2} \alpha$, mesmo na presença de corpo lúteo funcional (PINHEIRO et al., 1998). Entretanto, outros trabalhos realizados em raças zebuínas têm mostrado desde baixas - menores que 40\% (HARDIN; WARNICK; FIELDS, 1980; LANDIVAR; GALINA; DUCHATEAU, 1985) - até elevadas taxas de manifestação de cio - superiores a 70\% (BASILE; BENEDITO, 1980; LOPEZ-BARBELLA; MARTINEZ; GAVALDON, 1981; OYEDIPE; VOH; MARIRE, 1986) - após a administração de prostaglandina.

A $\mathrm{PGF}_{2} \alpha$ pode ser utilizada em combinação com progestágenos para melhorar a sincronização do estro (KASTELIC et al., 1997; MACMILLAN; PETERSON, 1993; MACMILLAN; TAUFA; DAY, 1995; MADUREIRA, 1995; ODDE, 1990; SMITH et al., 1984), especialmente quando aplicada 24 ou 48 horas antes da retirada do dispositivo. A luteólise induzida pela $\mathrm{PGF}_{2} \alpha$, de acordo com Schmitt et al. 
(1996), permitiu um crescimento mais uniforme do folículo pré-ovulatório durante o intervalo entre a aplicação do luteolítico e a retirada do dispositivo, por induzir uma secreção pulsátil de LH.

\subsubsection{Progesterona e PROgestágenos}

A utilização de hormônios esteróides para a sincronização do estro em bovinos teve início na década de 60 (HANSEL; CONVEY, 1983). Os tratamentos com progestágenos realizados àquela época tinham o objetivo de simular e controlar a extensão da fase luteal. Eram tratamentos de longa duração e, apesar de sincronizarem o estro com precisão, as inseminações artificiais após esse estro resultavam em baixa taxa de prenhez (GORDON, 1976; WISHART, 1972).

O primeiro relato sobre o uso de estrógenos como agentes luteolíticos em conjunto com progestágenos é de Wiltbank et al. (1965). O estradiol foi utilizado como agente luteolítico e o progestágeno para inibir o desenvolvimento do corpo lúteo em fêmeas recém ovuladas, ou para prevenir a ovulação no final do ciclo (WISHART; YOUNG, 1974). Posteriormente, essa combinação foi registrada como um produto comercial denominado SyncroMate B (SMB) - constituído por um implante hidrônico subcutâneo de norgestomet $(6 \mathrm{mg})$ utilizado por 9 dias, associado a uma injeção intramuscular (i.m.) de valerato de estradiol $(5 \mathrm{mg})$ e norgestomet (3 mg), aplicada no dia da colocação do implante (WILTBANK; GONZALES-PADILLA, 1975). O SyncroMate B induz o cio em 77 a $100 \%$ dos animais tratados, mas a maioria dos trabalhos constantes da literatura aponta taxas superiores a $90 \%$ (ODDE, 1990). Entretanto, a taxa de concepção de estros induzidos pelo SyncroMate B varia bastante - entre 33 e 68\% para Odde (1990), e entre 14 e 60\% 
para Kesler e Favero (1996) -, sendo influenciada pelo dia do ciclo estral em que o tratamento é iniciado (ODDE, 1990) e pela condição corporal dos animais (DUNN; KALTEMBACH, 1980).

O valerato de estradiol, à semelhança da $\mathrm{PGF}_{2} \alpha$, não é capaz de promover a luteólise nos primeiros cinco dias do ciclo estral (WILTBANK et al., 1996). Posteriormente foi lançado outro dispositivo, denominado Crestar, semelhante ao SMB, porém com uma tecnologia de liberação diferenciada - o progestágeno é impregnado em silicone. Essa tecnologia permitiu a diminuição da dose de norgestomet (3mg - KASTELIC et al., 1997) e possibilitou uma liberação mais constante (KESLER; FAVERO; TROXEL, 1995).

Também estão disponíveis no mercado dispositivos intravaginais de liberação de progesterona indicados para programas de sincronização de cio e ovulação. Os principais são: CIDR, com 1,9g de progesterona (MACMILLAN et al., 1991), PRID, com 1,55 g de progesterona (WINKLER et al., 1977) e DIB, com 1,0 g de progesterona (BÓ; BARUSELLI; MARTÍNEZ, 2003).

A administração de estradiol associado à progesterona induz a atresia do folículo dominante e a emergência de uma nova onda de desenvolvimento folicular (ADAMS; EVANS; RAWLINGS, 1992; BÓ et al., 1995), por diminuir a freqüência dos pulsos de LH (KINDER et al., 1996; MIHM; DISKIN; ROCHE, 1996). Diferentes tipos de estrógenos podem ser utilizados para esse fim. Bó et al. (1993a) relatam a indução de atresia do folículo dominante após a aplicação de $5 \mathrm{mg}$ de valerato de estradiol. Entretanto, a atresia foi incompleta quando o hormônio foi aplicado no meio ou no final da fase de crescimento do folículo dominante, e o intervalo entre o tratamento e a emergência da nova onda mostrou-se variável. Os autores atribuem esses achados à supressão da liberação do FSH e ao atraso na emergência de 
nova onda folicular que, por sua vez. foi associado ao aumento das concentrações plasmáticas de estrógeno por cinco a seis dias após a aplicação do valerato de estradiol.

O $17 \beta$ estradiol associado à progesterona e ao CIDR por sete dias foi testado por Bó et al. (1994) para induzir a emergência de uma nova onda folicular. Os autores observaram aumento nas concentrações de estrógenos 6 horas após a aplicação, concentrações estas que declinaram para valores basais após 42 horas. Essa aplicação resultou na emergência de uma nova onda folicular 4,3 $\pm 0,2$ dias após o tratamento, e em alto grau de sincronização da ovulação (75\% do animais ovularam entre 72 e 84 horas após a retirada do dispositivo). Resultados semelhantes foram observados em zebuínos por Tribulo et al. (1995).

O benzoato de estradiol (BE) também pode ser utilizado para indução de uma nova onda folicular. A aplicação de $2 \mathrm{mg}$ desse estrógeno em combinação com progesterona resultou em emergência de onda após 4,1 40,1 dias, com amplitude de 3,5 a 5 dias (CACCIA; BÓ, 1998; MORENO et al., 2001).

A associação entre um dispositivo de liberação de progesterona e um estrógeno, portanto, permite a sincronização da onda de desenvolvimento folicular. A retirada do dispositivo, associada a uma dose de $\mathrm{PGF}_{2} \alpha$, sincroniza a ovulação. Entretanto, diferentes investigações testaram formas de induzir um pico de LH para melhorar o grau de sincronia da ovulação e, conseqüentemente, os resultados da inseminação artificial em tempo fixo. O benzoato de estradiol mostrou-se eficiente nesse sentido: a aplicação de $0,75 \mathrm{mg}$ ou $1 \mathrm{mg}$ desse estrógeno sintético 24 horas após a retirada do dispositivo induziu o pico de LH e a ovulação 16 e 40 horas após a aplicação, respectivamente (MACMILLAN; BURKE, 1996; MACMILLAN; PETERSON, 1993). 


\subsection{INSEMINAÇÃO ARTIFICIAL EM TEMPO FIXO (IATF) COM DISPOSITIVOS DE LIBERAÇÃO LENTA DE PROGESTERONA}

\subsubsection{FATORES QUE INTERFEREM NOS RESULTADOS DE PRENHEZ}

Quando se utiliza um dispositivo de liberação lenta de progesterona, o protocolo padrão de IATF consiste na indução de uma nova onda de desenvolvimento folicular, que é feita com a inserção do dispositivo associado a um estrógeno injetável, normalmente o benzoato de estradiol (CACCIA; BÓ, 1998; MACMILLAN; PETERSON, 1993; MORENO et al., 2001; YELICH, 2002). Alguns estudiosos utilizam, no momento da inserção do dispositivo associado a um estrógeno injetável, também uma dose de progesterona injetável, mas essa progesterona adicional não se mostrou vantajosa na indução de uma nova onda e na taxa de ovulação ao final do tratamento (BÓ; BARUSELLI; MARTíNEZ, 2003), e nas taxas de prenhez após a IATF (BÓ, 2000). A retirada do dispositivo é realizada sete ou oito dias depois da inserção e habitualmente, nesse momento, um luteolítico ( $\mathrm{PGF}_{2 a}$ ou análogo) é aplicado. A indução da ovulação geralmente é feita com outra dose de estradiol 24 horas após a retirada do dispositivo (CUTAIA et al., 2001a; LEMASTER et al., 1999), e a IATF é realizada de 52 a 56 horas após a retirada do dispositivo. Ambas as doses de estradiol são essenciais ao protocolo: a supressão de qualquer uma delas diminui as taxas de prenhez: Yelich (2002) comenta sobre a primeira, e Colazo et al. (1999) informam sobre a segunda. O protocolo aqui descrito pode ser considerado como um padrão, mas a literatura registra algumas algumas alterações nesse esquema.

O tempo de inserção do dispositivo foi discutido por Bó, Baruselli e Martínez em publicação datada de 2003. Em novilhas Bos indicus, a inserção por oito dias 
tendeu a apresentar melhores resultados do que a inserção por sete dias (COLAZO et al., 1999): $54,1 \%(40 / 74)$ vs. $39,4 \%$ (28/71). Outros trabalhos não relatam diferenças no uso de CIDR por sete ou oito dias em novilhas européias (BÓ, 2000) ou cruzadas (YELICH, 2002).

Dados ultra-sonográficos obtidos após tratamentos com dispositivos de progesterona por sete dias demonstram que a ovulação ocorre em média 66 horas após a retirada do implante (CUTAIA et al., 2001b). Assim, e considerando que os espermatozóides necessitam de 8 a 12 horas para atingir o local de fertilização e serem capacitados (WILMUT; MOLLER, 1984), a IATF deve ser realizada entre 52 e 56 horas após a retirada do implante.

Para testar o melhor momento para a IATF foram realizados dois experimentos, relatados por Cutaia et al. (2003a). No primeiro, que utilizou vacas européias e cruzadas com condição corporal entre 2,5 e 3,5 (1 a 5) com 60 a 90 dias pós parto, foi aplicada uma dose de $2 \mathrm{mg}$ de benzoato de estradiol no momento da inserção dos dispositivos DIB; decorridos sete dias, os dispositivos foram retirados e uma dose de cloprostenol foi administrada; a indução da ovulação foi feita com 1mg de benzoato de estradiol 24 horas após a retirada do dispositivo, e a IATF foi realizada 48 ou 54 horas depois da retirada do dispositivo. O segundo experimento foi semelhante ao primeiro, mas as vacas utilizadas eram zebuínas, com cria e condição corporal média de 3; os resultados dos dois experimentos foram semelhantes. Não houve diferença significativa entre a IATF realizada 48 ou 54 horas após a retirada do dispositivo, mas as taxas de prenhez foram numericamente superiores nos animais submetidos à IATF 54 horas depois dessa retirada: 51,4\% $(108 / 210)$ vs. $45,5 \%(96 / 211)$. 
Em investigação semelhante, realizada em gado europeu no Canadá, Whittaker et al. (2002) observaram tendência a maiores taxas de prenhez para animais inseminados entre 53,4 e 57,5 horas (57\%), em relação àqueles inseminados entre 47 e 50 horas (45\%) após a retirada do dispositivo.

Os resultados de fertilidade de um rebanho guardam estreita relação com a nutrição (WILTBANK, 2003). Os escores de condição corporal são uma forma prática de avaliar a situação nutricional do animal que, em raças de corte, influencia a ciclicidade ovariana e as taxas de prenhez (BARUSELLI et al., 2003a; CUTAIA et al., 2003a; D'OCCHIO; NEISH; BROADHURST, 1990; VISCARRA et al., 1998). Em recente revisão, Cutaia et al. (2003a) avaliaram dados de 6857 IATFs realizadas entre 1999 e 2002. Os resultados mostram alta correlação entre os escores de condição corporal (1 a 5 ) e as taxa de prenhez $\left(R^{2}=0,9\right)$. As taxas para escores de 1,$5 ; 2 ; 2,5 ; 3 ; 3,5$ e 4 foram, respectivamente: $27,8 \% ; 46,5 \% ; 52,3 \% ; 57,7 \% ; 57,7 \%$ e $57,6 \%$. As taxas também foram maiores para vacas cíclicas $(56,3 \%)$ do que para vacas em anestro (47,0\%). Baruselli et al. (2003a) agruparam informações de 735 IATFs de fêmeas zebuínas com crias, e avaliaram os resultados em função do escore de condição corporal (1 a 5): as taxas de concepção de animais com escores 3; 3,5 e 4 foram, respectivamente, cerca de 39\%; 46\% e 55\%. Uma avaliação livre dos resultados desse trabalho sugere que o aumento do escore de condição corporal leva a uma diminuição da variação dos resultados de taxa de prenhez.

\subsubsection{Efeito do Anestro na Inseminação Artificial em Tempo Fixo}

Na maioria dos casos, o anestro é conseqüência da falha de ovulação do folículo dominante. Essa falha é decorrente da baixa concentração de gonadotrofinas, que não estimula a síntese de estradiol pelas células da granulosa 
do folículo ovariano em quantidades suficientes para induzir o estro e o pico préovulatório de LH (JOLLY et al., 1995; ROCHE; CROWE; BOLAND, 1992). Os tratamentos com progesterona ou progestágenos podem melhorar os resultados de prenhez de animais em anestro. A exposição a níveis elevados de progesterona parece ser pré-requisito para uma expressão do estro e para uma fase luteal normal (BÓ; ADAMS; MAPLETOFT, 2000; LUCY et al., 2001; YAVAS; JOHSON; WALTON, 1999). A exposição à progesterona exógena seguida por sua diminuição - priming de progesterona - aumenta a freqüência de pulsos de $\mathrm{LH}$, a produção de estrógenos foliculares, os receptores para LH e melhora a luteinização de animais em anestro (ROCHE; CROWE; BOLAND, 1992). Trabalhos mais recentes mostram que as concentrações plasmáticas de progesterona, após o fornecimento exógeno desse hormônio, influenciam os padrões de crescimento folicular e a ovulação. Após tratar animais em anestro e cíclicos com dispositivos de progesterona por sete dias. Vilela et al. (2003) observaram que os animais em anestro apresentaram maior crescimento folicular do que os animais cíclicos. Carvalho (2004) tratou novilhas zebuínas, cruzadas e européias com CIDR por oito dias, aplicando ou não uma dose de $\mathrm{PGF}_{2 \alpha}$ no primeiro dia da inserção do dispositivo. Os animais que receberam o luteolítico apresentaram menores concentrações plasmáticas de progesterona e taxas mais elevadas de crescimento folicular e ovulação. Novilhas cruzadas e européias cíclicas apresentaram maiores concentrações plasmáticas de progesterona do que novilhas zebuínas. Entretanto, as concentrações plasmáticas de progesterona das novilhas zebuínas aumentaram de $3,9 \mathrm{ng} / \mathrm{ml}$ no dia 0 - somente progesterona luteal -, para $8,4 \mathrm{ng} / \mathrm{ml}$ no terceiro dia depois da inserção do dispositivo - progesterona luteal somada à do dispositivo -, decrescendo para 6,9ng/ml decorridos oito dias da inserção. Já nos animais cruzados, os valores correspondentes a esses dias foram, respectivamente, $3,5 \mathrm{ng} / \mathrm{ml}, 6,8 \mathrm{ng} / \mathrm{ml}$ e $3,9 \mathrm{ng} / \mathrm{ml}$ e, nos europeus, 3,2ng/ml, 4,6ng/ml e 3,9ng/ml, respectivamente. O autor concluiu 
que as fêmeas zebuínas apresentaram maiores concentrações plasmáticas de progesterona porque têm menor capacidade de metabolizar esse hormônio.

Baruselli et al. (2002) elaboraram uma estação reprodutiva que consistia em IATF no primeiro dia, observação de cio durante 45 dias e monta natural por mais 45 dias. Os animais foram tratados com CIDR - inserção do dispositivo associado a $2 \mathrm{mg}$ de benzoato de estradiol e $50 \mathrm{mg}$ de progesterona -; o dispositivo foi retirado depois de oito dias, quando foi aplicada uma dose de 0,150mg de d-cloprostenol; após 24 horas foi injetado $1 \mathrm{mg}$ de benzoato de estradiol; a IATF foi realizada 54 horas após a retirada do dispositivo. Outro grupo foi tratado com o protocolo CRESTAR - implante com $3 \mathrm{mg}$ de norgestomet associado a $5 \mathrm{mg}$ de valerato de estradiol e 3mg de norgestomet injetável -; o implante foi mantido por nove dias e, 24 horas após a sua retirada aplicou-se $1 \mathrm{mg}$ de benzoato de estradiol; a IATF foi realizada 54 horas após a retirada do implante. O grupo controle foi inseminado por 45 dias e depois foi colocado com touros por mais 45 dias. A taxa de concepção após a IATF do grupo CIDR foi de 52\% (52/100), e a do grupo CRESTAR foi de 42,7\% (44/103). Após 45 dias de inseminação com observação de cio, a taxa de serviço do grupo CIDR foi de 45,8\% (25/48), e aquela do grupo CRESTAR foi de $44,1 \%$ (26/59), ambas superiores à do grupo controle - 23,4\% (22/94) -, mostrando que o tratamento induziu os animais à ciclicidade. Não houve diferenças nas taxas de concepção à IA entre os grupos CIDR, CRESTAR e controle durante o período de inseminação com observação de cios $(68,2 \%, 80,8 \%$ e $81,8 \%$, respectivamente). A taxa de prenhez da IATF+IA foi superior para os animais tratados com CIDR (65\% 65/100) e com CRESTAR $(60,2 \%$ - 62/103) em relação àquela do grupo controle $(19,1 \%$ - 18/94). A taxa de prenhez no final do repasse com os touros não diferiu entre CIDR-B, CRESTAR e controle (79\%, $88,3 \%$ e $80,9 \%$, respectivamente), 
entretanto os tratamentos anteciparam o parto na estação subseqüente em 39,4 dias para o grupo CIDR e em 29,3 dias para o grupo CRESTAR em relação ao grupo controle.

Outra forma de melhorar os resultados das taxas de prenhez em programas de IATF é a utilização de gonadotrofinas, principalmente a gonadotrofina coriônica eqüina (eCG) no momento da retirada dos dispositivos de progesterona (MACMILLAN; BURKE, 1996; MACMILLAN; PETERSON, 1993; ROCHE; CROWE; BOLAND, 1992).

Baruselli et al. (2003b) compararam a IATF com dispositivos de progesterona com e sem o uso de eCG. Para isso, trabalharam com vacas Nelore com média de 75 dias pós-parto. Os animais do grupo controle receberam um dispositivo de progesterona (CIDR) associado a 2mg de benzoato de estradiol; após oito dias o dispositivo foi retirado e administrou-se $0,150 \mathrm{mg}$ de d-cloprostenol; uma segunda dose de BE foi administrada 24 horas após a retirada do dispositivo e a IATF foi realizada entre 52 e 56 horas depois da retirada do dispositivo. O grupo tratamento foi submetido ao mesmo protocolo, apenas acrescido de $400 \mathrm{UI}$ de eCG i.m. administrados quando da retirada do implante. O uso de eCG aumentou significativamente a taxa de concepção após a IATF (38,9\% vs. 55,1\%). As taxas de concepção também variaram em função da atividade ovariana. O tratamento não influenciou as taxas de concepção de animais com corpo lúteo no início do tratamento ( $64 \%$ vs. $55,5 \%$, respectivamente, para eCG e controle). Já a avaliação dos animais em transição - folículos maiores que 8mm: 50\% vs. 34,4\%, respectivamente, para eCG e controle- e em anestro - folículos menores que 8mm; $56,5 \%$ vs $29,4 \%$, respectivamente, para eCG e controle - revelou que o eCG melhora o desenvolvimento do folículo dominante e a taxa de ovulação e concepção. 
Investigação semelhante foi implementada por Cutaia et al. (2003b), porém usando PRID em animais cruzados (Braford), de baixa condição corporal e entre 60 e 90 dias pós-parto. Tais autores obtiveram taxas de concepção de 35,5\% no protocolo com eCG, e de $26,7 \%$ no protocolo sem eCG. O eCG não interferiu nas taxas de prenhez de animais que apresentavam corpo lúteo $(34,6 \%$ vs $33,3 \%)$ e folículos maiores $(33,3 \%$ vs. $29,1 \%)$ no início do tratamento, mas melhoraram os resultados daqueles que apresentavam folículos menores $(38,8 \%$ vs. $17,6 \%)$. comparando esses dois trabalhos, Bó, Baruselli e Martínez (2003) sugeriram que o eCG em protocolos com dispositivos de progesterona associados ao benzoato de estradiol é mais compensador quando utilizado em animais em condições de anestro. Em investigação posterior, Cutaia et al. (2003c) avaliaram os efeitos da aplicação de $400 U$ I de eCG no dia 6 após a inserção ou na retirada (dia 8) do DIB em animais europeus e cruzados com baixa condição corporal (2, em escala de 1 a 5), comparando-os a um grupo controle que não recebeu eCG. O dias de aplicação do eCG não provocou diferenças, mas os animais tratados com eCG no dia 6 ou no dia 8 apresentaram taxas de prenhez superiores àquela dos animais que não receberam eCG $(66,1 \%$ vs. $61,4 \%$ vs. $46,5 \%$, respectivamente). A análise desses resultados agrupando os animais tratados com eCG e comparando-os com aqueles do controle - pelo teste de qui quadrado mostrou que o eCG aumentou as taxas de prenhez dos animais que apresentavam corpo lúteo no início do tratamento $(p=0,04)$ : $73,0 \%$ (54/74) vs. $55,5 \%(26 / 47)$, folículos maiores ( $p=0,01): 62,0 \%(67 / 108)$ vs. $42,6 \%$ (29/68), o que não ocorreu entre os animais com folículos menores ( $p=0,27)$ : $54,2 \%$ $(32 / 59)$ vs. $40,7 \%(11 / 27)$.

Trabalhando com 644 vacas Brangus inseminadas em tempo fixo com protocolos com e sem eCG, Baruselli et al. (2003c) não observaram efeitos 
benéficos dessa gonadotrofina $(61,8 \%$ vs. $59,6 \%)$. Entretanto, o uso de eCG melhorou os resultados da IATF na fêmeas com menos de 40 dias de parição (58\% vs. $45 \%)$, escore de condição corporal (1-5) menor que $2,5(57,1 \%$ vs. $45,3 \%)$ e primíparas $(67,6 \%$ vs. $57,3 \%)$. Esse estudo também mostrou que é possível substituir a indução da ovulação com o benzoato de estradiol por gonadotrofina corônica humana (hCG) ou hormônio liberador de gonadotrofina $(\mathrm{GnRH})$ administrados no momento da IATF, 54 horas após a retirada do dispositivo, sem prejuízo das taxas de prenhez.

Um programa de inseminação artificial em tempo fixo foi implementado por Vilela (2004) em 453 vacas Nelore multíparas entre 34 e 74 dias pós-parto e taxa de ciclicidade de 23\%. Nesse programa, à base de $\operatorname{GnRH}(\mathrm{D} 0)-\mathrm{PGF}_{2 \alpha}(\mathrm{D} 6)-$ GnRH+IATF(D8), o autor testou o uso ou não de CIDR por seis dias após a primeira dose de $\mathrm{GnRH}$. Após a IATF os animais tratados e os controles foram colocados com touros até que a estação reprodutiva completasse 90 dias. Os resultados obtidos mostraram que vacas com menor escore de condição corporal apresentam melhor resposta quando se utiliza a progesterona. A taxa de prenhez à IATF para esse protocolo foi de $32,5 \%$. O tratamento resultou em menor intervalo partoconcepção em relação ao controle com touros - 62,9 vs. 96,7 dias para animais em anestro (antecipação de prenhez de 33,8 dias), e 58,9 vs. 74,7 dias para animais ciclando (antecipação de 15,8 dias), respectivamente.

A qualidade do sêmen interfere fortemente no resultado da IATF. Fullenwilder et al. (2001) observaram grande variação (de 0 a 80\%) nas taxas de prenhez para diferentes touros. Esses estudiosos obtiveram taxas de prenhez de $47,2 \%$ e $53,3 \%$ em dois lotes inseminados após um protocolo de sete dias com 
CIDR, aplicação de benzoato de estradiol 24 horas e IATF 48 horas após a retirada do dispositivo.

\subsection{DISPOSITIVOS INTRAVAGINAIS DE LIBERAÇÃO LENTA DE PROGESTERONA}

O primeiro dispositivo intravaginal de liberação lenta de progesterona disponível comercialmente foi o Progesterone Releasing Intravaginal Device (PRID), citado inicialmente por Winkler et al. (1977). Esse dispositivo possui uma alma de aço inox em formato espiralado, recoberta por silicone impregnado com 1,55 gramas de progesterona. Em 1993, Macmillan e Peterson descreveram um outro tipo de dispositivo, denominado Controlled Internal Drug Release (CIDR), formado por uma alma de nylon em formato de $\mathrm{T}$, recoberta por uma membrana de silicone impregnada com 1,9 gramas de progesterona (19 gramas de silicone com $10 \%$ de progesterona). A espessura da membrana varia entre $0,5 \mathrm{~mm}$ e $5 \mathrm{~mm}$ mas, na maior parte do dispositivo, varia entre $1,5 \mathrm{~mm}$ e $1,8 \mathrm{~mm}$. A superfície de contato do dispositivo é de $120 \mathrm{~cm}^{2}$ (RATHBONE et al., 1998).

Ao comparar as concentrações de progesterona plasmáticas em vacas ovariectomizadas após o uso do PRID e do CIDR por 14 dias, Munro (1987) não observou diferenças entre os dispositivos. No primeiro dia após a inserção, foram constatadas concentrações plasmáticas de progesterona ao redor de $10 \mathrm{ng} / \mathrm{ml}$ para ambos os dispositivos. Tais concentrações diminuíam diariamente até cerca de $5 \mathrm{ng} / \mathrm{ml}$ no oitavo dia, e $4 \mathrm{ng} / \mathrm{ml}$ no $14^{\circ}$ dia. Também Uehlinger et al. (1995) não observaram diferenças entre as concentrações plasmáticas de progesterona após o uso do PRID e do CIDR em vacas ovariectomizadas, mas tais concentrações foram bastante inferiores àquelas relatadas por Munro (1987): entre 3 e 4 ng/ml no primeiro 
dia, caindo para 1 a $2 \mathrm{ng} / \mathrm{ml}$ no oitavo dia e para cerca de $1 \mathrm{ng} / \mathrm{ml}$ após 14 dias. De acordo com Rathbone et al. (1998), comparações entre autores acerca de valores absolutos de concentrações plasmáticas de progesterona podem ser dúbias em função das variações do método de radioimunoensaio. Isto é notado principalmente em trabalhos realizados nos anos 80 . Mais recentemente, o aumento da precisão e da acurácia dos ensaios radioimunológicos pode permitir esse tipo de comparação.

A quantidade de progesterona liberada depende principalmente do tempo de inserção do dispositivo. A taxa diária de liberação de progesterona varia pouco entre dispositivos (MACMILLAN et al., 1990; PETERSON; HENDERSON, 1990), e provavelmente entre animais e diferentes trabalhos (RATHBONE et al., 1998).

Após a aplicação do CIDR em vacas ovariectomizadas há uma rápida fase de absorção inicial e o pico de concentração plasmática se dá em duas horas (UEHLINGER et al., 1995), mantém-se por 24 a 48 horas e cai de $6 \mathrm{ng} / \mathrm{ml}$ para cerca de $3 \mathrm{ng} / \mathrm{ml}$ em sete dias. Após a retirada do dispositivo, a concentração de progesterona cai para os níveis basais (RATHBONE et al., 1998). Macmillan e Peterson (1993) observaram variação nas concentrações iniciais de progesterona após a inserção dos dispositivos (de 4,2 a 7,2ng/ml). Essa variação também foi observada por Peterson e Henderson (1990), e não foi acompanhada por variação na quantidade de progesterona residual nos dispositivos utilizados, sugerindo que a variação das concentrações plasmáticas desse hormônio decorre principalmente da capacidade dos animais de metabolizar a progesterona.

Em 2000, um novo produto, o Dispositivo Intravaginal Bovino (DIB) foi disponibilizado no mercado. Com uma alma de nylon em formato de $\mathrm{V}$, recoberta por silicone, esse dispositivo se assemelha ao CIDR em tamanho e superfície de contato (cerca de $120 \mathrm{~cm}^{2}$ ), mas possui uma dose de progesterona menor $(1 \mathrm{~g})$ em uma 
mesma massa de silicone $(19 \mathrm{~g})$. A espessura da membrana é um pouco maior que a do CIDR, e a concentração de progesterona na massa de silicone é menor (5,3\%). Investigações sobre esse produto mostram concentrações de progesterona plasmáticas iniciais de 5-6ng/ml, que caem para cerca de $2-3 \mathrm{ng} / \mathrm{ml}$ depois de dois dias e permanecem constantes até o sétimo ou oitavo dia (BÓ; BARUSELLI; MARTINEZ, 2003). Não há avaliações que comparem o DIB a outros dispositivos quanto à liberação e às concentrações plasmáticas de progesterona. Entretanto, quando compararam o DIB ao CIDR em protocolos de inseminação artificial em tempo fixo, Bó et al. (2002) não observaram diferença entre as taxas de prenhez desses dispositivos em vacas não lactantes: (61,5\% vs. 60,7\%, respectivamente, para DIB e CIDR), assim como Marques et al. (2003) em vacas Nelores com 66 dias pós-parto inseminadas em tempo fixo em protocolo com o uso e 300Ul de eCG: $53,7 \%(79 / 147)$ vs. $48,5 \%(67 / 138)$, respectivamente. Marques et al. (2003) também compararam a reutilização de dispositivos CIDR e DIB, e obtiveram taxas semelhantes de prenhez para vacas cujas condições eram semelhantes àquelas do experimento anterior (41,9\% vs. $46,8 \%$, respectivamente). Esses dados permitem concluir que a diminuição da dose de progesterona do dispositivo é uma forma efetiva de diminuição de custo de produção, sem perda de desempenho.

Em um experimento em arranjo fatorial em vacas cruzadas paridas, Cutaia et al. (2001b) testaram os efeitos de uma aplicação de 50mg de progesterona junto com a primeira dose de benzoato de estradiol na inserção do dispositivo, e de dispositivos reutilizados ou novos. Não houve diferença entre o uso ou não da progesterona injetável associada ao benzoato de estradiol, mas os autores obtiveram melhores resultados de prenhez com dispositivos reutilizados do que com dispositivos novos - 59,5\% (114/191) vs. 49,5\% (99/200), respectivamente -, 
sugerindo que menores concentrações de progesterona no final do crescimento do folículo dominante podem ter um efeito benéfico sobre o crescimento deste e sobre a taxa de ovulação. 


\section{MATERIAL E MÉTODO}

\subsection{EXPERIMENTO 1 - EFEITO DA ÁREA DE SUPERFÍCIE DE CONTATO E DA DOSE DE PROGESTERONA DO DISPOSITIVO NA CONCENTRAÇÃO PLASMÁTICA DE PROGESTERONA}

\subsubsection{ANIMAIS E LOCAL DO EXPERIMENTO}

O experimento foi realizado no Departamento de Reprodução Animal da Faculdade de Medicina Veterinária e Zootecnia da Universidade de São Paulo, localizado na cidade de São Paulo (SP), durante o período de novembro de 2001 a junho de 2002.

Foram utilizadas qutro novilhas meio sangue Nelore/Simental, com 2,5 anos de idade e pesos variando entre 350 e $380 \mathrm{~kg}$.

Os animais foram submetidos a ovariectomia pelo flanco esquerdo e permaneceram um mês em repouso antes do inicio do experimento. O intervalo entre ensaios também foi sempre superior a um mês. Os animais foram alimentandos com concentrado e feno de gramínea durante toda a duração do experimento.

\subsubsection{TRATAMENTOS}

Para que pudessem ser testados os efeitos da área de superfície de contato e da dose de progesterona, foram confeccionados dispositivos de plástico (polipropileno) nos quais se encaixavam tubos de silicone com $1,3 \mathrm{~cm}$ de diâmetro, $1,3 \mathrm{~mm}$ de espessura de parede e diferentes tamanhos. 
Os tubos de silicone foram confeccionados com medidas que permitissem áreas externas de $50 \mathrm{~cm}^{2}$ e $100 \mathrm{~cm}^{2}$. Foi utilizado elastômero de silicone misturado com progesterona, vulcanizado a $110^{\circ} \mathrm{C}$ em molde de aço inoxidável por 15 minutos. Os tubos foram elaborados de forma a construir cinco diferentes tipos de dispositivos:

PROTÓTIPO P50-0,5: $50 \mathrm{~cm}^{2}$ de superfície externa e 0,5g de progesterona.

PROTÓTIPO P50-1,0: $50 \mathrm{~cm}^{2}$ de superfície externa e 1,0g de progesterona.

PROTÓTIPO P50-2,0: $50 \mathrm{~cm}^{2}$ de superfície externa e 2,0g de progesterona.

PROTÓTIPO P100-1,0:100 $\mathrm{cm}^{2}$ de superfície externa e 1,0g de progesterona.

PROTÓTIPO P100-2,0:100 $\mathrm{cm}^{2}$ de superfície externa e 2,0g de progesterona.

Cada tipo de dispositivo foi utilizado em duas novilhas por vez. A divisão dos dispositivos que seriam colocados antes do ensaio foi realizada por sorteio.

Após lavagem e assepsia das vulvas das novilhas, os dispositivos foram colocados nas vaginas com o auxílio de um espéculo vaginal.

\subsubsection{Coleta de MATERIAL}

Foram coletadas amostras de sangue da veia jugular em tubos de vácuo heparinizados ${ }^{1}$. As amostras usadas como controle foram colhidas antes do início do tratamento, e novas coletas foram realizadas 24 horas e sete dias depois da inserção dos dispositivos. O sangue foi mantido refrigerado por até no máximo 30 minutos após a coleta, e depois centrifugado a $2000 \mathrm{~g}$ por 10 minutos $^{2}$. O plasma foi envasado em tubos de plástico. O material era identificado e depois congelado a $-20^{\circ} \mathrm{C}$ para posterior dosagem de progesterona por radioimunoensaio. 


\subsubsection{DOSAGEM DAS CONCENTRAÇÕES PLASMÁTICAS DE PROGESTERONA}

As amostras de plasma foram submetidas à dosagem das concentrações plasmáticas de progesterona utilizando-se um "kit" comercial de radioimunoensaio em fase sólida, seguindo as recomendações protocolares do fabricante ${ }^{3} \mathrm{~A}$ sensibilidade do teste foi de $0,05 \mathrm{ng} / \mathrm{ml}$.

\subsubsection{ANÁLISE ESTATÍSTICA}

Os dados foram submetidos à Analise de Regressão Múltipla. Para isso, foi utilizado o procedimento REG do programa estatístico $\mathrm{SAS}^{4}$. Foram avaliados os efeitos da área de superfície externa do silicone e da dose de progesterona no dispositivo (preditores da equação de regressão) sobre a concentração de progesterona sangüínea depois de 24 horas e de sete dias da colocação do dispositivo.

\subsection{EXPERIMENTO 2 - EFEITO DE DIFERENTES DISPOSITIVOS DE PROGESTERONA SOBRE AS CONCENTRAÇÕES PLASMÁTICA DE PROGESTERONA DURANTE 8 DIAS}

\subsubsection{ANIMAIS E LOCAL DO EXPERIMENTO}

O experimento foi realizado na Fazenda Nelore do Coração, localizada em Cornélio Procópio (PR). Foram utilizadas 20 novilhas Nelore, com dois anos de idade e peso ao redor de $300 \mathrm{~kg}$.

4 SAS institute Inc, Cary, NC, EUA, 1999-2000 
Todos os animais foram avaliados por ultra-sonografia no dia da colocação dos dispositivos. Somente foram utilizadas as fêmeas que se encontravam em anestro no momento da avaliação - definido como ausência de corpo lúteo e de folículos com diâmetro superior a 8mm. Foram excluídos do experimento os animais que apresentaram concentração plasmática de progesterona inicial - antes da colocação do dispositivo - superior a $1 \mathrm{ng} / \mathrm{ml}$ : cinco animais foram excluídos por esse motivo. Durante o período experimental os animais foram mantidos alimentando-se exclusivamente de pasto.

\subsubsection{TRATAMENTOS}

Foram testados os seguintes dispositivos intravaginais:

GRUPO CIDR dispositivos CIDR $^{5}$, com $120 \mathrm{~cm}^{2}$ de área de superfície de contato e $1,9 \mathrm{~g}$ de progesterona (4 animais)

GRUPO DIB dispositivos $\mathrm{DIB}^{6}$, com $120 \mathrm{~cm}^{2}$ e $1 \mathrm{~g}$ de progesterona (3 animais)

GRUPO P50-1.5 dispositivos experimentais com $50 \mathrm{~cm}^{2}$ de área de superfície externa e $1,5 \mathrm{~g}$ de progesterona (3 animais)

GRUPO P50-1.0 dispositivos experimentais com $50 \mathrm{~cm}^{2}$ de área de superfície externa e $1,0 \mathrm{~g}$ de progesterona (5 animais)

As áreas das superfícies externas dos dispositivos foram medidas com réguas flexíveis e paquímetro. No caso do CIDR, esses dados foram semelhantes àqueles divulgados pela empresa (ao redor de $120 \mathrm{~cm}^{2}$ ).

As novilhas foram divididas aleatoriamente em 5 grupos, e os tratamentos sorteados para cada grupo.

Após lavagem e assepsia das vulvas das novilhas, os dispositivos foram colocados nas vaginas com o auxílio de um espéculo vaginal. A retirada foi feita tracionando-se o dispositivo pela cauda.

\footnotetext{
CIDR® - Interag, Nova Zelândia

6 DIB® - Syntex, Argentina
} 


\subsubsection{Coleta De MATERIAL}

Foram coletadas amostras de sangue da veia jugular em tubos de vácuo heparinizados ${ }^{7}$. As amostras colhidas antes do início do tratamento foram usadas apenas como controle. As amostras utilizadas para traçar o perfil de liberação de progesterona foram colhidas diariamente, com início 24 horas depois da colocação dos dispositivos, até o oitavo dia. O sangue foi mantido refrigerado por até no máximo 30 minutos após a coleta e depois centrifugado a $2000 \mathrm{~g}$ por 10 minutos $^{8}$. 0 plasma foi envasado em tubos de plástico. O material foi identificado e depois congelado a $-20^{\circ} \mathrm{C}$ para posterior dosagem de progesterona por radioimunoensaio.

\subsubsection{DOSAGEM DAS CONCENTRAÇÕES PLASMÁtICAS DE PROGESTERONA}

As amostras de plasma foram submetidas a dosagem da concentração de progesterona utilizando-se um kit comercial de radioimunoensaio em fase sólida, seguindo as recomendações protocolares do fabricante ${ }^{9}$. A sensibilidade do teste foi de $0,05 \mathrm{ng} / \mathrm{ml}$.

\subsubsection{AnÁlise estatística}

Os dados de concentração plasmática de progesterona foram submetidos às seguintes análises estatísticas. Primeiramente, para avaliar as concentrações iniciais e finais, utilizou-se o procedimento GLM do programa estatístico SAS. As análises de variância testaram os efeitos de tipo de dispositivo (CIDR; DIB; P50-1,0 e P501.5) sobre as concentrações plasmáticas de progesterona 24 horas e oito dias após

\footnotetext{
7 Sistema Vacutainer - Becton Dickinson Company, EUA

8 Centrifuga 206/2-BL, Fanem, Brasil
} 
a inserção do dispositivo. Para uma segunda análise foram compilados os dados de concentração de progesterona plasmática de cada animal para o calculo de regressões simples dessa variável em função do dia de coleta. Foi montada uma tabela com os valores de inclinação da equação de cada animal (a inclinação estima a queda diária da concentração). Esses dados foram analisados pelo procedimento GLM do programa estatístico SAS. O modelo matemático testou os efeitos dos tratamento sobre a queda diária de progesterona plasmática (inclinação da regressão). As médias foram comparadas pelo teste de tukey

\subsection{EXPERIMENTO 3 - TAXA DE CONCEPÇÃO DA INSEMINAÇÃO ARTIFICIAL EM TEMPO FIXO (IATF) EM VACAS NELORE E CRUZADAS TRATADAS COM DOIS DIFERENTES DISPOSITIVOS COMPARADOS COM MONTA NATURAL, EM ESTAÇÃO REPRODUTIVA DE 90 DIAS}

\subsubsection{ANIMAIS E LOCAL DO EXPERIMENTO}

O experimento foi realizado na fazenda Paim, localizada em Gurupi (TO), durante os meses de fevereiro a maio de 2003. Foram utilizadas 220 vacas multíparas com bezerros entre 50 e 70 dias de idade Destes animais, 110 eram cruzadas Nelore-Europeu e 110 eram Nelore.

Uma amostra aleatória de 50 animais (28 Nelores e 22 Cruzados) foi submetida a avaliação ovariana por palpação retal no dia da colocação dos dispositivos para estimar o nível de ciclicidade do rebanho. A cada animal também foi atribuída uma nota de escore corporal (1 a 5). Os animais permaneceram, durante o período experimental, alimentando-se exclusivamente de pasto e sal mineral.

9 Coat-ACount, Diagnostic Products Corporation, Los Angeles, EUA 


\subsubsection{TRATAMENTOS}

Os seguintes dispositivos foram testados nos animais:

GRUPO DIB protocolo de inseminação em tempo fixo padrão com dispositivos DIB (60 animais)

GRUPO V50-1.5 protocolo de inseminação em tempo fixo padrão com dispositivos experimentais com $50 \mathrm{~cm}^{2}$ de área de superfície externa e $1,5 \mathrm{~g}$ de progesterona (100 animais)

GRUPO TOUROs animais colocados somente em monta natural (60 animais)

Os protocolos experimentais podem ser vistos na Figura 1.

\section{Esquema para a IATF}

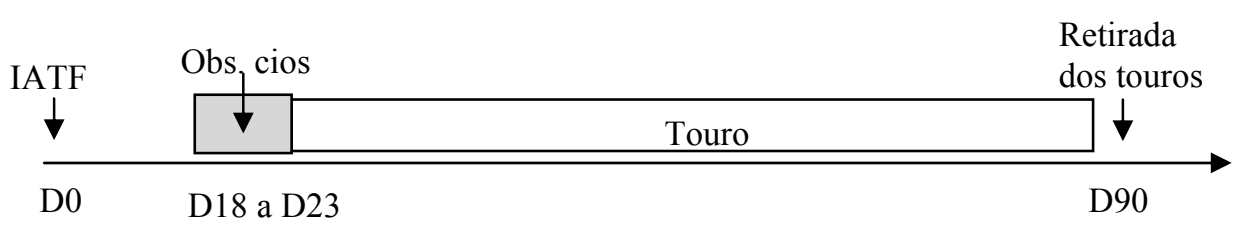

\section{Esquema para Touros}

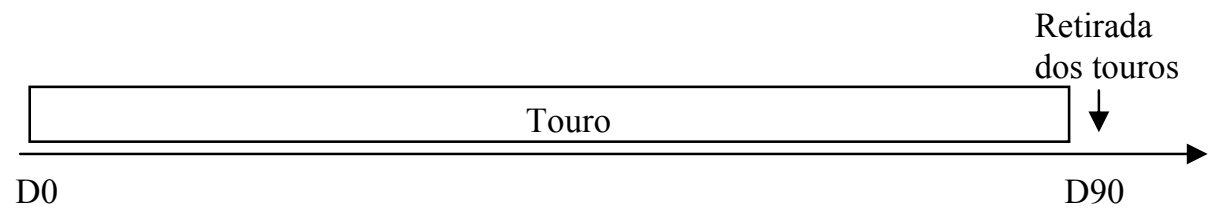

Tratamentos

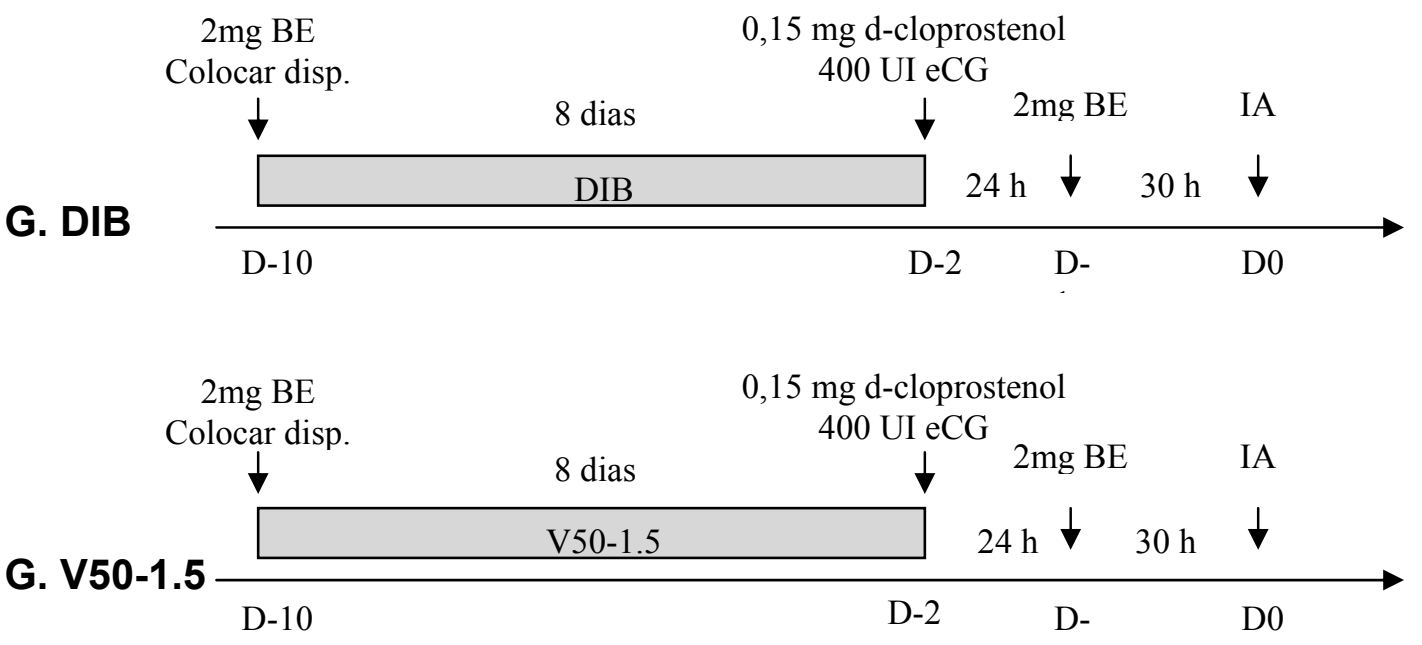

Figura 1 - Protocolos experimentais 
Os animais foram divididos aleatoriamente. Os grupos experimentais foram balanceados quanto ao grupo genético (Nelore ou Cruzadas). Tomou-se o cuidado de comparar as médias de escore de condição corporal e desvio após a divisão dos lotes, para evitar vícios experimentais $(2,5 \pm 0,4 ; 2,4 \pm 0,4$ e $2,5 \pm 0,4$, para os tratamentos DIB, V50-1,5 e Touro, respectivamente). O escore de condição corporal das vacas cruzadas foi um pouco superior ao das Nelore: $2,6 \pm 0,4$ vs. $2,2 \pm 0,4$, respectivamente, embora todos os animais recebessem o mesmo manejo.

Todos os animais dos grupos experimentais receberam uma dose de benzoato de estradiol ${ }^{10}$ (2mg i.m.) no inicio do tratamento (dia 0 ), momento da colocação do dispositivo vaginal (DIB ${ }^{11}$ ou $\left.\mathrm{V} 50-1.5\right)$. Os dispositivos foram retirados oito dias depois (D8). No momento da retirada, foram administrados um análogo da prostaglandina $F_{2} \alpha^{12}\left(0,150 \mathrm{mg}\right.$ de $d$-cloprostenol i.m.) e $400 \mathrm{Ul}$ de eCG ${ }^{13}$ i.m. Decorridas 24 horas da retirada do dispositivo (D9) foi aplicada uma segunda dose de benzoato de estradiol (1mg i.m.), e após 30 horas iniciou-se o procedimento de inseminação artificial, que não durou mais de 4 horas.

Uma observação de cios foi realizada do $18^{\circ}$ ao $23^{\circ}$ dia depois da IATF, para detecção dos cios de retorno. Essa observação foi feita durante uma hora pela manhã e uma hora no final da tarde. Todos os animais dos grupos tratados identificados em cio pela manhã foram inseminados à tarde, e todos aqueles identificados em cio à tarde foram inseminados na manhã do dia seguinte. Após 24 dias da primeira inseminação, todos os animais dos grupos tratados foram colocados com touros, em quantidade que mais se aproximasse da proporção de 1 macho para

\footnotetext{
10 RIC-BE - Syntex, Argentina

11 DIB- Syntex, Argentina

12 Prolise - Arsa -Argentina
} 
cada 25 fêmeas.

As fêmeas do grupo controle foram colocadas com touros no dia da primeira inseminação dos grupos tratados (D10). Todos os animais do experimento permaneceram com touros até o final da estação reprodutiva, que se encerrou 90 dias depois da IATF.

\subsubsection{FERTILIDADE DO SÊMEN E dOS TOUROS}

Nos grupos inseminados foi utilizado sêmen de um único touro. As partidas foram submetidas à avaliação de motilidade, vigor e concentração espermática e ao teste de termo-resistência rápido, sendo consideradas dentro dos padrões estabelecidos pelo Ministério da Agricultura Pecuária e Abastecimento Brasileiro. No grupo controle, foram utilizados touros previamente aprovados em avaliação andrológica.

Após lavagem e assepsia das vulvas, os dispositivos foram colocados nas vaginas dos animais, com o auxílio de um espéculo vaginal. A retirada foi feita tracionando-se o dispositivo pela cauda.

\subsubsection{PARÂMETROS ANALISADOS}

Os seguintes índices foram comparados entre os grupos experimentais:

1. Taxa de prenhez da IATF (TP-IATF): número de vacas prenhes por IATF dividido pelo total de vacas de cada grupo.

2. Taxa de retorno da IATF (TR-IATF): número de animais que retornaram ao cio 18 a 23 dias após a IATF dividido pelo total de vacas vazias de cada grupo.

13 Novormon - Syntex, Argentina 
3. Taxa de concepção da IA convencional (TC-IA): número de vacas prenhes por IA convencional dividido pelo total de vacas inseminadas após observação de cio.

4. Taxa de prenhez da IATF + IA convencional (TP-IA+IATF): número de vacas prenhes por IA (IATF+ IA convencional) sobre o total de vacas de cada grupo.

5. Taxa de prenhez no final da estação de monta de 100 dias (TP-final): total de vacas prenhes sobre o total de vacas de cada grupo após o final da estação reprodutiva.

6. Intervalo entre o tratamento (primeira IA) e o parto (ITP): intervalo em dias entre o dia da primeira inseminação nos grupos tratados ou colocação dos touros no grupo controle, e o parto dos animais.

\subsubsection{Avaliação dos parâmetros}

O diagnóstico de prenhez após a IATF e a IA foi realizado por palpação retal 100 dias após as primeiras inseminações. Novo toque foi realizado dois meses após o final da estação reprodutiva de 100 dias em todos os lotes. Os TP-IATF e o TP-IA foram calculadas pelo tempo de prenhez diagnosticado à palpação retal, cruzandose os dados com as datas da IATF e IA. Os intervalos entre tratamento e parto foram calculados após o nascimento dos animais.

\subsubsection{ANÁLISE ESTATíSTICA}

As taxas de prenhez, concepção e retorno para os diferentes tratamentos e escores de condição corporal foram comparadas pelo teste de qui-quadrado. 0 intervalo tratamento-parto (ITP) foi submetido à Análise de Variância, pelo procedimento GLM do programa estatístico SAS. O modelo matemático testou os efeitos de tratamento sobre a variável ITP. Comparações entre médias foram realizadas pelo teste de tukey. 


\subsection{EXPERIMENTO 4 - RESULtAdOS DA INSEMINAÇÃo ARTIFICIAL EM TEMPo FiXo (IATF) EM VACAS NELORE COMPARANDO DOIS TIPOS DE DISPOSITIVOS DE LIBERAÇÃO DE PROGESTERONA}

\subsubsection{ANIMAIS E LOCAL DO EXPERIMENTO}

O experimento foi realizado na fazenda Quinzão, localizada em Campo Grande (MS), durante os meses de fevereiro e março de 2004. Foram utilizados três lotes de vacas multíparas, entre 50 e 80 dias de paridas e escore de condição corporal entre 2,5 e 3 (em escala de 1 a 5), avaliado no dia do início dos tratamentos. Os dados de intervalo pós-parto foram estimados sobre a média do lote de parição em que os animais se encontravam (cada lote era formado por animais paridos em um intervalo de 15 dias). Foram utilizados nesse experimento 270 animais pertencentes a três lotes denominados: Lote 1 - 38 animais; Lote 2 - 94 animais e Lote 3 - 138 animais. Os animais foram distribuídos nos grupos experimentais de forma balanceada quanto à condição corporal, no caso dos lotes 1 e 2, e de forma totalmente aleatória no caso do lote 3.

Todos os animais dos lotes 1 e 2 foram avaliados previamente aos tratamentos por ultra-som ${ }^{14}$. Nessa avaliação os animais foram classificados em 3 classes, de acordo com a observação de suas estruturas ovarianas:

CLASSIFICAÇÃo A: animais que apresentaram corpo lúteo em um ou ambos os ovários.

CLASSIFICAÇÃo B: animais sem corpo lúteo, mas com um ou mais folículos de tamanho igual ou superior a $8 \mathrm{~mm}$.

CLASSIFICAÇÃO C: animais somente com folículos menores de 8mm

\footnotetext{
${ }^{14}$ Pie Medical -
} 
Os animais permaneceram durante o período experimental exclusivamente a pasto, suplementados apenas com sal mineral. A falta de chuvas naquela região durante o período do experimento manteve os animais em condições insatisfatórias de alimentação. As médias de peso e escore de condição corporal e a estimativa de intervalo pós-parto para os lotes do experimento podem ser observados na Tabela 1.

Tabela 1 - Médias de peso, escore de condição corporal e intervalo pós-parto de três lotes de animais submetidos à IATF. Campo Grande, 2004

\begin{tabular}{ccccccccc}
\hline \multirow{2}{*}{ Lotes } & \multirow{2}{*}{ Número } & \multicolumn{3}{c}{ DIB } & & \multicolumn{3}{c}{ V50-1.5 } \\
\cline { 3 - 4 } \cline { 7 - 9 } & & peso & ECC & IPP & & Peso & ECC & IPP \\
\hline Lote 1 & 38 & 386 & 2,6 & 63 & & 398 & 2,7 & 57 \\
Lote 2 & 94 & 365 & 2,6 & 73 & & 361 & 2,6 & 70 \\
Lote 3 & 138 & - & $*$ & 61 & & - & $*$ & 61 \\
\hline
\end{tabular}

* Os animais do lote 3 apresentavam escore de condição corporal entre 2,5 e 3, porém não foram avaliados individualmente.

\subsubsection{TRATAMENTOS}

Dentro de cada um dos 3 lotes dividiu-se aleatoriamente os animais em 2 grupos experimentais:

Os seguintes dispositivos foram testados nos animais:

GRUPO DIB protocolo de inseminação em tempo fixo padrão com dispositivos DIB (60 animais) - Figura 2

GRUPO V50-1.5 protocolo de inseminação em tempo fixo padrão com dispositivos experimentais com $50 \mathrm{~cm}^{2}$ de área de superfície externa e $1,5 \mathrm{~g}$ de progesterona (100 animais) - Figura 2

O protocolo de IATF utilizado nos grupos experimentais pode ser visto na Figura 2. Todos os animais dos grupos experimentais receberam uma dose de benzoato de estradiol ${ }^{15}$ ( $2 \mathrm{mg}$ i.m.) no inicio do tratamento (dia 0 ), momento da

15 RIC-BE - Syntex, Argentina 
colocação do dispositivo vaginal de liberação de progesterona (DIB ${ }^{16}$ ou V50-1.5). Os dispositivos foram retirados oito dias depois (D8). No momento da retirada foram administrados um análogo da prostaglandina $F_{2} \alpha^{17}(0,150 \mathrm{mg}$ de $d$-cloprostenol i.m.) e $400 U \mathrm{Ul}$ de $\mathrm{eCG}^{18}$ i.m. Decorridas 24 horas da retirada do dispositivo (D9) foi aplicada uma segunda dose de benzoato de estradiol (1mg i.m.), e após 30 horas iniciou-se o procedimento de inseminação artificial, que não durou mais que 4 horas. Os lotes 1; 2 e 3 foram inseminados nas seguintes datas, respectivamente: 1/2/2004; 18/3/2004 e 27/3/2004.

G. DIB

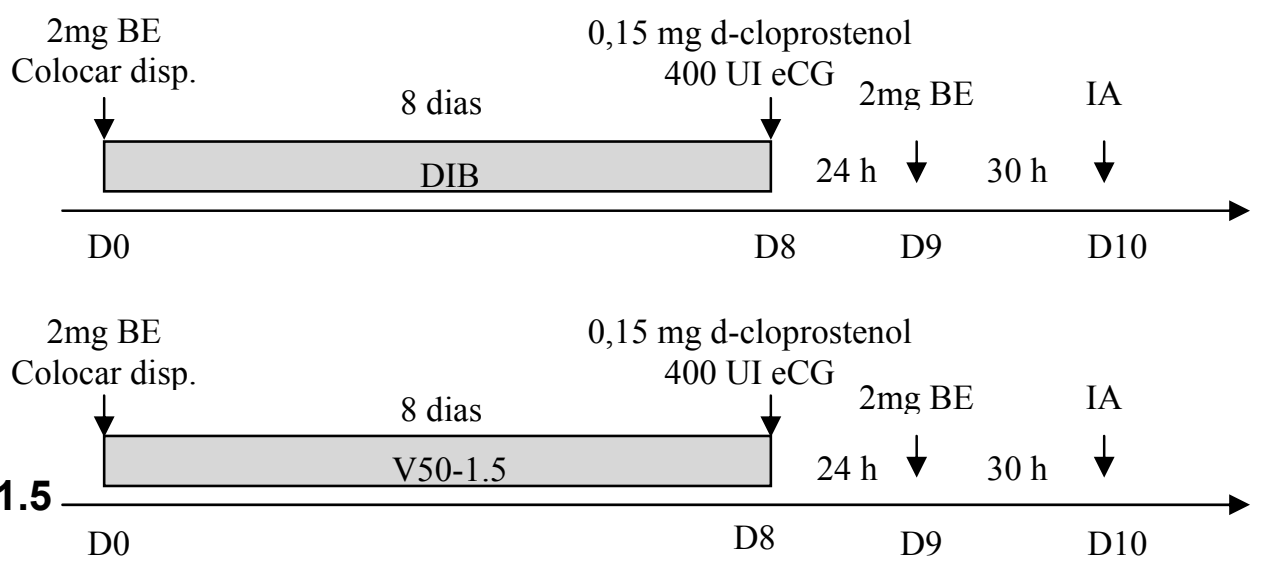

Figura 2 - Protocolos experimentais

\subsubsection{FERTILIDADE do SÊMEN}

No lote 1 foi utilizado sêmen de um único touro. Nos lotes 2 e 3 foram utilizadas doses de sêmen de dois touros em cada lote. Todas as partidas foram utilizadas previamente em inseminação convencional, tendo apresentado resultados semelhantes à média histórica da fazenda

\subsubsection{PARÂMETROS ANALISADOS}

\footnotetext{
16 DIB- Syntex, Argentina

17 Prolise - Arsa -Argentina
} 
As taxas de prenhez da IATF foram calculadas em função das seguintes variáveis:

1. Tratamento: comparação entre dois diferentes tipos de dispositivos (DIB vs. V501.5).

2. Classificação ovariana: comparação entre animais com diferentes classificações ovarianas (a vs. b vs. c)

3. Touro: comparação entre taxas de prenhez após o uso de sêmen de diferentes touros.

4. Seqüência de IA: comparação entre taxas de prenhez dos animais inseminados do início ao meio do período de inseminação, e de animais inseminados do meio ao final do período de inseminação - somente avaliados nos lotes 2 e 3.

5. Presença de muco no momento da IA - somente avaliado no lote 3

\subsubsection{DIAGNÓSTICO DE PRENHEZ}

Os diagnósticos das gestações foram realizados por ultra-som depois de 30 ou mais dias da IATF.

\subsubsection{ANÁLISE ESTATÍSTICA}

As taxas de prenhez foram comparadas pelo teste de qui-quadrado.

18 Novormon - Syntex, Argentina 


\section{RESULTADOS E DISCUSSÃO}

\subsection{EXPERIMENTO 1 - EFEITO DA ÁREA DE SUPERFÍCIE DE CONTATO E DA DOSE DE PROGESTERONA DO DISPOSITIVO NA CONCENTRAÇÕES PLASMÁTICAS DE PROGESTERONA}

Os resultados da análise de variância mostraram efeitos significativos da equação de regressão $(P<0,001)$ e dos preditores: área de superfície de contato $(P<0,001)$ e dose de progesterona $(P=0,036)$ sobre as concentrações plasmáticas de progesterona após 24 horas da inserção dos dispositivos. A equação, e algumas estimativas, podem ser vistas na Tabela 2.

O coeficiente de determinação da equação (R-square) ajustado pelo modelo foi de 0,94 . A regressão foi, portanto, bastante eficiente em controlar as fontes de variação das amostras.

Tabela 2 - Estimativas de concentrações plasmáticas de progesterona em $\mathrm{ng} / \mathrm{ml}$ em função da área de superfície de contato e da dose de progesterona em dispositivos após 24 horas de inserção. São Paulo, 2002

\begin{tabular}{lccc}
\hline Área & \multicolumn{3}{c}{ Dose de progesterona } \\
\cline { 2 - 4 } & 0,5 & 1,0 & 2,0 \\
\hline 50 & 2,21 & 2,47 & 2,98 \\
100 & 3,92 & 4,18 & 4,69 \\
\hline$\left[P 4_{24}\right]=0,238+0,0343$ área $+0,513$ dose & & \\
$\mathrm{R}^{2}: 0,94$ & & \\
\hline
\end{tabular}

Os resultados da análise de variância mostraram efeitos significativos da equação de regressão $(P<0,001)$ e do preditor dose de progesterona $(P=0,040)$, e 
tendência de significância da área de superfície de contato $(P=0,081)$ sobre as concentrações plasmáticas de progesterona após sete dias da inserção dos dispositivos. A equação e algumas estimativas podem ser vistas na Tabela 3.

O coeficiente de determinação da equação ajustado pelo modelo $\left(R^{2}\right)$ foi de 0,71. A regressão foi eficiente em controlar as fontes de variação das amostras.

Tabela 3 - Estimativas de concentrações plasmáticas de progesterona em ng/ml em função da área de superfície de contato e dose de progesterona em dispositivos após sete dias de inserção. São Paulo, 2002

\begin{tabular}{lccc}
\hline Área & \multicolumn{3}{c}{ Dose de progesterona } \\
\cline { 2 - 4 } & 0,5 & 1,0 & 2,0 \\
\hline 50 & 0,78 & 0,94 & 1,27 \\
100 & 1,05 & 1,22 & 1,55 \\
\hline$\left[P 4_{d 7}\right]=0,331+0,0056$ área $+0,329$ dose & \\
$R^{2}: 0,71$ & & \\
\hline
\end{tabular}

Quando se comparou a regressão das 24 horas com a do sétimo dia observou-se diminuição dos efeitos da dose de progesterona do dispositivo sobre as concentrações plasmáticas de progesterona. Para cada unidade de progesterona (1g) aumentada, a concentração plasmática aumentou 0,513ng/ml após 24 horas, e 0,329ng/ml após sete dias da inserção do dispositivo. O mesmo ocorreu em relação à área de superfície de contato do dispositivo, embora de maneira mais intensa: cada $1 \mathrm{~cm}^{2}$ de área de superfície de contato do dispositivo acrescenta $0,0343 \mathrm{ng} / \mathrm{ml}$ às 24 horas. e 0,0056ng/ml após sete dias. Nas diferentes áreas de superfície de contato e doses testadas há um efeito maior da área do que da dose sobre as concentrações plasmáticas de progesterona logo após a inserção do dispositivo; já no final do período de inserção esse quadro se inverte, ou seja, as concentrações 
plasmáticas de progesterona passam a ser mais influenciada pela dose do que pela superfície de contato.

A diminuição dos coeficientes de determinação das regressões do início ao final do período de inserção dos dispositivos indica que outras fontes de variação, além daquelas controladas pelo experimento, passam a atuar mais intensamente sobre as concentrações plasmáticas de progesterona com o decorrer do tempo. Isso deve ser levado em consideração ao se definir a dose e a área de superfície de contato de um novo dispositivo, pois gera a necessidade de aumentar a concentração plasmática média de progesterona no final do período de inserção para compensar o aumento da variação.

Existem poucos dados na literatura sobre concentrações plasmáticas de progesterona após o uso de dispositivos intravaginais, e informações sobre a relação entre superfície de contato e dose de progesterona não foram encontradas. As equações de regressão calculadas no presente experimento, quando aplicadas a um dispositivo com as características do CIDR, estimariam concentrações plasmáticas inicial e aos sete dias ao redor de $4,97 \mathrm{ng} / \mathrm{ml}$ e de $1,62 \mathrm{ng} / \mathrm{ml}$, respectivamente. Esses valores são diferentes dos achados de Munro (1987) - ao redor de $10 \mathrm{ng} / \mathrm{ml}$ no primeiro dia e de $5 \mathrm{ng} / \mathrm{ml}$ no oitavo dia -, mas se aproximam mais das concentrações obtidas por Uehlinger et al. (1995) - inicial de $6 \mathrm{ng} / \mathrm{ml}$, caindo para 3ng/ml em sete dias. Quando as equações de regressão foram aplicadas para o dispositivo DIB, os resultados foram: $4,87 \mathrm{ng} / \mathrm{ml}$ e 1,33ng/ml, respectivamente, para 24 horas e sete dias pós-inserção, não diferindo muito daqueles obtidos por Bó, Baruselli e Martinez. (2003) para esse mesmo dispositivo logo após a inserção (entre 5 e 6ng/ml), mas sim no sétimo dia $(2-3 \mathrm{ng} / \mathrm{ml})$. Entretanto, esse tipo de comparação pode ser prejudicado em função dos métodos de radioimunoensaio, principalmente em 
trabalhos anteriores a 1990 (RATHBONE et al., 1998), ou mesmo pela diferença de resposta dos animais, como descrevem Macmillan e Peterson (1993), que observaram concentrações iniciais de progesterona plasmática após a inserção dos dispositivos bastante variáveis - entre 4,2 e 7,2ng/ml - e Peterson e Henderson (1990), que verificaram variação nas concentrações plasmáticas não acompanhadas por variação na quantidade de progesterona residual nos dispositivos utilizados, sugerindo que a variação da progesterona plasmática após a inserção do dispositivo decorre, principalmente da capacidade dos animais de metabolizar esse hormônio. Outras fontes de variação que podem prejudicar o uso dessas equações como preditoras de concentrações plasmáticas de progesterona são as diferenças de espessura das membranas dos dispositivos - embora no presente estudo a espessura tenha sido constante, nos dispositivos comerciais ela varia - e o tipo de silicone utilizado.

\subsection{EXPERIMENTO 2 - EFEITO DE DIFERENTES DISPOSITIVOS DE PROGESTERONA SOBRE AS CONCENTRAÇÕES PLASMÁTICA DE PROGESTERONA DURANTE 8 DIAS}

As primeiras análises de variância mostraram efeitos significativos dos tipos de dispositivos sobre as concentrações plasmáticas iniciais de progesterona (24 horas após a inserção do dispositivo - $\mathrm{P}=0,007$ ), e tendência de efeito do tipo de dispositivo sobre a concentração plasmática aos oito dias $(P=0,07)$. As médias iniciais e finais de concentrações plasmáticas de progesterona para os diferentes dispositivos são mostradas na Tabela 4. 
Tabela 4 - Progesterona plasmática de novilhas após inserção de diferentes dispositivos de progesterona. Cornélio Procópio, 2002

\begin{tabular}{lcc}
\hline Dispositivo & \multicolumn{2}{c}{$\left[\mathrm{P}_{4}\right]$} \\
\cline { 2 - 3 } & 24 horas & 8 dias \\
\hline CIDR & $7,7 \pm 2,8^{\mathrm{a}}$ & $3,3 \pm 0,7^{\mathrm{a}}$ \\
DIB & $4,5 \pm 0,75^{\mathrm{b}}$ & $2,6 \pm 2,0^{\mathrm{a}}$ \\
P50-1,5 & $5,9 \pm 2,5^{\mathrm{b}}$ & $3,0 \pm 2,4^{\mathrm{a}}$ \\
P50-1,0 & $2,1 \pm 0,5^{\mathrm{c}}$ & $1,1 \pm 0,27^{\mathrm{b}}$ \\
\hline
\end{tabular}

A segunda análise de variância mostrou efeito significativo $(P=0,04)$ do tipo de dispositivo sobre as quedas diárias de progesterona (a inclinação das regressões). O teste de médias não mostrou diferenças significativas entre as quedas diárias das concentrações plasmáticas de progesterona para os diferentes dispositivos $(P>0,05)$. A Figura 3 mostra as concentrações plasmáticas de progesterona para cada dispositivo em função do tempo.

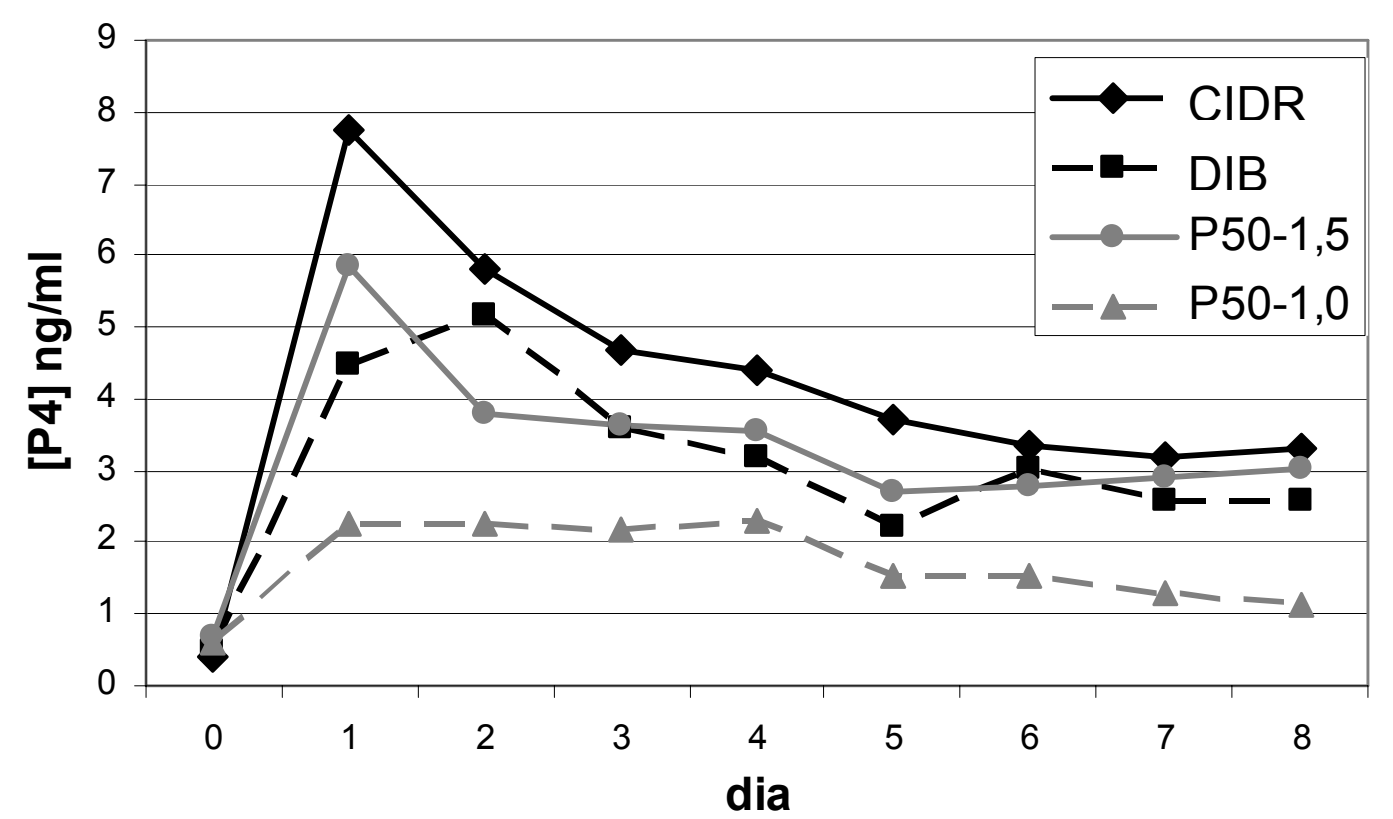

Figura 3 - Concentrações plasmáticas de progesterona durante 8 dias de inserção de 5 diferentes tipos de dispositivos vaginais de liberação lenta de progesterona. Cornélio Procópio, 2002 
Os resultados do experimento mostram que existem diferenças de concentrações plasmáticas de progesterona para os dispositivos logo após a sua inserção e ao final do período de uso. Também mostram que a queda diária das concentrações plasmáticas de progesterona varia entre dispositivos. Essas diferenças estão ligadas às variações de concentração de progesterona e superfície de contato, como mostra o experimento 1. O P50-1,0 apresentou concentrações plasmáticas inferiores àquelas dos demais dispositivos no início e no final do período de inserção. O CIDR apresentou a maior concentração no primeiro dia pós inserção, mas não houve diferença significativa entre CIDR, DIB e P50-1,5 transcorridos oito dias de inserção. Com exceção do P50-1,0 todos os dispositivos apresentaram um padrão de liberação com um pico bem caracterizado no início, e uma queda constante - até níveis ao redor de $3 \mathrm{ng} / \mathrm{ml}$ - após 8 dias. Já o protótipo P50-1,0 mostrou um perfil de liberação com um pico mais baixo no início e uma queda mais lenta das concentrações. Essas diferenças de perfil estão ligadas principalmente à dose de progesterona, visto que os protótipos P50-1,5 e P50-1,0 possuem a mesma área de superfície de contato. As concentrações plasmáticas de progesterona 24 horas pós-inserção observadas no experimento 2 diferiram daquelas previstas pelas equações do experimento 1: as concentrações iniciais previstas foram de $2,72 \mathrm{ng} / \mathrm{ml}$ e 2,47ng/ml, e aquelas observadas para os dispositivos P50-1,5 e P50-1,0 foram de $5,9 \mathrm{ng} / \mathrm{ml}$ e 2,1 ng/ml, respectivamente. Ao final do período de inserção, as concentrações esperadas seriam de $1,1 \mathrm{ng} / \mathrm{ml}$ e $0,94 \mathrm{ng} / \mathrm{ml}$, porém os resultados encontrados foram 3,6ng/ml e 1,1ng/ml para P50-1,5 e P50-1,0, respectivamente. Tais dados mostram que o uso desse tipo de equação como preditor de concentrações plasmáticas de progesterona pode ter um uso limitado. Essa discrepância entre os resultados esperados e aqueles observados deve ocorrer 
menos por variações da técnica de dosagem por radioimunoensaio entre experimentos do que por diferenças entre as características dos animais do experimento 1 - novilhas cruzadas, peso entre 350 e 380 e ovariectomizadas - e do experimento 2 - novilhas zebuínas, com peso de cerca de $300 \mathrm{~kg}$ e pré-púberes. Peterson e Henderson (1990) mostraram que a variação encontrada nas concentrações plasmáticas de progesterona de diferentes animais é mais influenciada pela capacidade dos animais em metabolizar a progesterona do que pela liberação do hormônio pelos dispositivos. Carvalho (2004) mostrou que novilhas cruzadas e européias cíclicas apresentaram maiores concentrações plasmáticas de progesterona do que novilhas zebuínas também cíclicas. Logo após a colocação do dispositivo, as concentrações plasmáticas de progesteronas das zebuínas eram de de $3,9 \mathrm{ng} / \mathrm{ml}$ - dia 0 , somente progesterona luteal -, aumentando para $8,4 \mathrm{ng} / \mathrm{ml}$ no terceiro dia pós-inserção - progesterona luteal somada à do dispositivo - e caindo para $6,9 \mathrm{ng} / \mathrm{ml}$ após oito dias da inserção. Para animais cruzados os mesmos valores foram, respectivamente de 3,5; 6,8 e 3,9ng/ml e para europeus, respectivamente, 3,2; 4,6 e 3,9. Os dados desse autor mostram a importância da variação individual, e também o efeito do grupo genético, sobre essas concentrações. Os zebuínos metabolizam mais lentamente a progesterona do que os cruzados e os europeus, sendo esse, provavelmente o principal fator de diferenciação entre as concentrações plasmáticas dos protótipos nos experimentos 1 e 2.

Também um efeito residual das seguidas inserções do experimento 1 poderia causar a variação nos resultados, alterando as taxas de metabolismo desse hormônio. Contudo, não existem estudos que possam esclarecer se inserções repetidas de dispositivos podem provocar esse efeito, e deve-se ainda considerar que o intervalo entre inserções foi sempre superior a um mês. 


\subsection{EXPERIMENTO 3 - TAXA DE CONCEPÇÃO DA INSEMINAÇÃO ARTIFICIAL EM TEMPO FIXO (IATF) EM VACAS NELORE E CRUZADAS TRATADAS COM 2 DIFERENTES DISPOSITIVOS COMPARADOS COM MONTA NATURAL, EM ESTAÇÃO REPRODUTIVA DE 90 DIAS}

A avaliação ovariana dos animais antes do experimento mostrou que o rebanho contava com um baixo nível de ciclicidade: somente 2\% (1/50) dos animais apresentaram corpo lúteo palpável.

Não houve diferença significativa entre os tratamentos com os dispositivos DIB e P50-1,5 quanto à taxa de prenhez da IATF $(P=0,89)$, taxa de retorno da IATF $(P=0,45)$, taxa de concepção da IA convencional $(P=0,11)$, taxa de prenhez da IATF + IA convencional $(P=0,74)$ e taxa de prenhez no final da estação reprodutiva de 90 dias $(P=0,66)$. Os resultados podem ser vistos na Tabela 5.

Tabela 5 - Taxas de prenhez da IATF(TP-IATF), taxas de retorno da IATF (TRIATF), taxas de concepção da IA convencional (TC-IA), taxas de prenhez da IATF + IA convencional (TP-IA+IATF), taxas de prenhez no final da estação reprodutiva de 90 dias (TP-final) e intervalo tratamentoparto (ITP) de vacas sob programa IATF com dois tipos de dispositivos de liberação lenta de progesterona ou cobertas por touros. Gurupi, 2003

\begin{tabular}{lcccccc}
\hline Trat. & TP & TR & TC & TP & TP & ITP \\
& IATF & IATF & IA & IATF+IA & final & (dias $\pm D P$ ) \\
\hline \multirow{2}{*}{ DIB } & $30 \%$ & $40,5 \%$ & $76,4 \%$ & $51,6 \%$ & $80 \%$ & $317 \pm 12^{\mathrm{a}}$ \\
& $(18 / 60)$ & $(17 / 42)$ & $(13 / 17)$ & $(31 / 60)$ & $(48 / 60)$ & \\
P50-1,5 & $31 \%$ & $49,3 \%$ & $52,9 \%$ & $49 \%$ & $77 \%$ & $317 \pm 13^{\mathrm{a}}$ \\
& $(31 / 100)$ & $34 / 69$ & $18 / 34$ & $(49 / 100)$ & $(77 / 100)$ & \\
Touro & - & - & - & - & $71 \%$ & $365 \pm 44^{\mathrm{b}}$ \\
& & & & & $(43 / 60)$ & \\
\hline
\end{tabular}

Letras diferentes na mesma coluna: $\mathrm{P}<0,05$

As taxas de prenhez da IATF foram inferiores àquelas observadas na literatura para esse tipo de tratamento. Trabalhos que utilizaram protocolo 
semelhante ao do presente experimento, com o uso de eCG, são recentes: Baruselli et al. (2003b) obtiveram, em vacas Nelore com 75 dias pós-parto e protocolo igual àquele aqui empregado, taxa de prenhez de 55,1\%. Cutaia et al. (2003c), que trabalharam com vacas européias e cruzadas com baixa condição corporal, também obtiveram elevada taxa de prenhez $(61,4 \%)$ com protocolo igual ao deste experimento. Em outro trabalho, Baruselli et al. (2003c) conseguiram, em vacas cruzadas Brangus com boa condição corporal e alimentação, taxa de prenhez de $61,8 \%$. Entretanto, outros autores, como Cutaia et al. (2003b), também obtiveram baixas taxas de prenhez com o mesmo protocolo - $35,5 \%$ em animais cruzados entre 60 a 90 dias pós-parto e com baixa condição corporal.

Os baixos resultados de prenhez deste trabalho podem estar relacionados ao baixo escore de condição corporal e à fertilidade do sêmen utilizado. O escore de condição corporal dos animais do presente estudo influenciou significativamente a taxa de retorno da IATF $(P=0,01)$, a taxa prenhez da IATF + IA convencional $(P=0,02)$ e a taxa de prenhez no final da estação reprodutiva de 100 dias $(P=0,01)$, mas não teve efeitos sobre a taxa de prenhez da IATF $(P=0,12)$ e a taxa de concepção da IA convencional $(P=0,42)$. Tais achados podem ser vistos na Tabela 6. 
Tabela 6 - Taxas de prenhez após a IATF(TP-IATF), taxas de retorno da IATF (TRIATF), taxas de concepção da IA convencional (TC-IA), taxas de prenhez da IATF + IA convencional (TP-IA+IATF), taxas de prenhez no final da estação reprodutiva de 100 dias (TP-final) e intervalo tratamento-parto (ITP) de vacas em função do escore de condição corporal (1 a 9). Gurupi, 2003

\begin{tabular}{lcccccc}
\hline ECC & TP & TR & TC & TP & TP & ITP \\
& IATF & IATF & IA & ATF+IA & final & (dias $\pm D P)$ \\
\hline \multirow{2}{*}{2} & $21,4 \%$ & $18,1 \%$ & $50,0 \%$ & $28,6 \%$ & $52,9 \%$ & $323 \pm 17$ \\
& $(3 / 14)$ & $(2 / 11)$ & $(1 / 2)$ & $(4 / 14)$ & $(9 / 17)$ & \\
2,5 & $23,6 \%$ & $34,0 \%$ & $52,9 \%$ & $36,9 \%$ & $71,1 \%$ & $329 \pm 30$ \\
& $(15 / 65)$ & $(17 / 50)$ & $(9 / 17)$ & $(24 / 65)$ & $(64 / 90)$ & \\
3 & $36,5 \%$ & $68,1 \%$ & $65,6 \%$ & $64,9 \%$ & 83,3 & $328 \pm 36$ \\
& $(27 / 74)$ & $(32 / 47)$ & $(21 / 32)$ & $(48 / 74)$ & $(85 / 102)$ & \\
3,5 & $57,1 \%$ & 0 & & $57,1 \%$ & $90,9 \%$ & $338 \pm 37$ \\
& $(4 / 7)$ & $(0 / 3)$ & - & $(4 / 7)$ & $(10 / 11)$ & \\
\hline
\end{tabular}

A relação entre as taxas de prenhez à IATF e os escores de condição corporal foi bem estabelecida (BARUSELLI et al., 2003a, 2004; CUTAIA et al., 2003a). Após analisarem dados de 6857 IATFs. entre 1999 e 2002, Cutaia et al. (2003a) encontraram alta correlação entre os escores de condição corporal (1 a 5) e a taxa de prenhez $\left(R^{2}=0,9\right)$. As taxas para escores de 1,$5 ; 2 ; 2,5 ; 3 ; 3,5$ e 4 foram, respectivamente: $27,8 \% ; 46,5 \% ; 52,3 \% ; 57,7 \% ; 57,7 \%$ e $57,6 \%$. Baruselli et al. (2003a) agruparam dados de 735 IATFs de fêmeas zebuínas com cria e avaliaram os resultados em função do escore de condição corporal (1 a 5). As taxas de concepção de animais com escores 3; 3,5 e 4 foram de, aproximadamente, 39\%, $46 \%$ e $55 \%$. No presente experimento, os baixos escores de condição corporal (ECC) poderiam ter reduzido as taxas de prenhez mesmo com o uso de eCG, hormônio que tem se mostrado eficaz em melhorar os resultados de animais nessas condições, conforme citado por Baruselli et al. (2003b, c); Cutaia et al. (2003b). Os animais trabalhados no experimento 3 apresentaram média de escore de condição 
corporal igual a 2,5. Em estudo retrospectivo, Baruselli et al. (2004) observaram elevadas taxas de concepção à IATF quando utilizaram eCG em animais com baixo escore de condição corporal. Os resultados obtidos por tais estudiosos para esses animais em função do ECC foram: ECC 2,0: 47,6\%; ECC 2,5: 56,9\%; ECC 3,0: $58,4 \%$. Esses dados sugerem que o baixo escore de condição corporal dos animais do experimento 3 não foi o principal fator a diminuir o resultado da IATF, já que animais com escore menor ou igual obtiveram resultados bem superiores àqueles aqui observados. Por outro lado, pode se observar na Tabela 6 altas taxas de retorno à IATF, principalmente nos animais com melhor escore de condição corporal (65,6\%); isso, indica que as falhas de concepção não ocorreram pelo baixo ECC, e sim por falha no processo de inseminação, provavelmente decorrente de problemas com o sêmen utilizado. Fullenwiilder et al. (2001) também observaram grande impacto da fertilidade do sêmen sobre as taxas de prenhez à IATF, que variaram entre 0 e $80 \%$.

Vacas cruzadas apresentaram maiores taxas de prenhez após a IATF $(P=0,025)$ que vacas Nelore $(38,7 \%$ vs. $22,5 \%)$. Esses resultados são uma provável conseqüência dos melhores escores de condição corporal desse grupo no início do experimento.

O intervalo tratamento parto (ITP) foi influenciado pelo tratamento $(P<0,001)$, mas não sofreu efeito de escore de condição corporal $(P=0,81)$. As médias de ITP em função dos tratamentos e em função dos escores de condição corporal podem ser observadas nas Tabelas 5 e 6 , respectivamente.

O intervalo tratamento parto foi semelhante para os dispositivos P50-1,5 e DIB: 317 dias para ambos os grupos $(P=0,49)$. A média de ITP dos animais submetidos ao tratamento hormonal foi inferior àquela dos animais sem o tratamento 
(apenas cobertos por touros): 317 dias vs. 365 dias $(P<0,001)$. Poucos trabalhos avaliaram o efeito desses tipos de tratamento sobre o retorno à ciclicidade, o intervalo entre partos ou o intervalo parto-concepção.

Comparando protocolos de IATF com CIDR ou com implantes auriculares (Crestar), Baruselli et al. (2002) observaram diminuição do intervalo tratamento-parto de 39,3 dias e 29,3 dias, respectivamente, para os dois produtos, em comparação com um grupo controle inseminado de maneira convencional. As taxas de prenhez à IATF foram de, respectivamente, $52 \%$ e $42,7 \%$, e as taxas de prenhez no final de uma estação de monta de 90 dias foram de $79,0 \% ; 88,3 \%$ e $80,9 \%$, respectivamente para CIDR, Crestar e IA convencional. As taxas de prenhez no final da estação de monta deste experimento foram semelhantes às de Baruselli et al. (2002), embora as taxas de prenhez à IATF tenham sido inferiores às dos citados autores. No presente experimento os controles foram cobertos com touros, o que deve ter aumentado a antecipação da prenhez por eliminar as falhas de detecção de cio, explicando em parte a maior antecipação. Também o uso de eCG deve ter contribuído para a maior antecipação de prenhez aqui encontrada.

Recentemente, Vilela (2004) realizou um programa de inseminação artificial em tempo fixo que apresentava algumas semelhanças com o experimento 3 - 453 vacas Nelore multíparas, entre 34 e 74 dias pós-parto e baixa taxa de ciclicidade (23\%). Após a IATF, os animais tratados e os controles foram colocados com touros até que a estação reprodutiva completasse 90 dias. A taxa de prenhez à IATF obtida também foi semelhante à do presente experimento: $32,5 \%$. O tratamento resultou em antecipação do parto de 33,8 dias para animais em anestro, e de 15,8 dias para animais cíclicos. Os animais utilizados pelo autor, entretanto, apresentavam intervalo pós-parto mais curto (34 a 74 dias) e escores de condição corporal maiores $(3,5)$, do 
que aqueles desta investigação, além de ter procedido à interrupção da amamentação dos animais durante o protocolo e não haver utilizado eCG no protocolo.

As diferenças de condição dos animais e do protocolo aqui utilizado e aqueles dos trabalhos de Baruselli et al. (2002); Vilela (2004) dificultam a identificação dos fatores mais relacionados a essa antecipações de prenhez, porém é possível concluir que todos os tratamentos influenciaram positivamente essa antecipação, e que os animais em anestro tiveram maior antecipação que os animais cíclicos. Por fim, um importante fator que deve ter acentuado a antecipação de prenhez no presente experimento em relação aos trabalhos de Baruselli et al. (2002); Vilela (2004) foi o uso de eCG. Essa gonadotrofina pode melhorar os resultados de prenhez em programas de IATF (BARUSELLI et al., 2003b, c; CUTAIA et al., 2003b, c; MACMILLAN; BURKE, 1996; MACMILLAN; PETERSON, 1993; ROCHE; CROWE; BOLAND, 1992), notadamente em animais em anestro (BARUSELLI et al., 2003b; CUTAIA et al., 2003b) e em animais com baixos escores de condição corporal (BARUSELLI et al., 2003b), como no caso de boa parte dos animais do presente experimento.

Os escores de condição corporal não influenciaram significativamente o ITP. Provavelmente isso ocorreu porque não havia uma grande variação desses escores entre os grupos tratados e o grupo controle, e também por causa do uso do eCG. $\mathrm{O}$ eCG tende a aproximar as taxas de prenhez de animais com escores inferiores e superiores de condição corporal. Isso pode ser observado no trabalho de Baruselli et al. (2003b), e talvez possa ser extrapolado às avaliações de intervalo tratamentoparto. 


\subsection{EXPERIMENTO 4 - RESULTAdOS DA INSEMINAÇÃo ARTIFICIAL EM TEMPO FiXo (IATF) EM VACAS NELORE COMPARANDO DOIS TIPOS DE DISPOSITIVOS DE LIBERAÇÃO DE PROGESTERONA}

Não houve diferença significativa entre os tratamentos com os dispositivos DIB e com os dispositivos P50-1,5 quanto à taxa de prenhez após a IATF dentro de cada um dos três lotes $(P=0,76 ; P=0,92$ e $P=0,39$, respectivamente para os lotes $1 ; 2$ e 3), ou para todos os lotes em conjunto $(P=0,51)$. Os resultados podem ser vistos na Tabela 7.

Tabela 7 - Taxas de prenhez da IATF de vacas Nelore com dois tipos de dispositivos de progesterona. Campo Grande, 2004

\begin{tabular}{cccc}
\hline Trat. & DIB & P50-1,5 & Total \\
\hline \multirow{2}{*}{ Lote 1} & $50 \%$ & $45,0 \%$ & $47,4 \%$ \\
& $(9 / 18)$ & $(9 / 20)$ & $(18 / 38)$ \\
Lote 2 & $51,1 \%$ & $52,1 \%$ & $51,6 \%$ \\
& $(24 / 47)$ & $(25 / 48)$ & $(49 / 95)$ \\
Lote 3 & $46,3 \%$ & $39,1 \%$ & $45,4 \%$ \\
& $(32 / 69)$ & $(27 / 69)$ & $(59 / 138)$ \\
\hline \multirow{2}{*}{ Total } & $48,5 \%$ & $44,5 \%$ & $46,5 \%$ \\
& $(65 / 134)$ & $(61 / 137)$ & $(126 / 271)$ \\
\hline
\end{tabular}

O experimento 4 foi realizado para comparar as taxas de prenhez dos dois tipos de dispositivos em uma situação de melhores resultados da IATF. Mesmo trabalhando com condições de alimentação inferiores às ideais - o que resultou em animais com baixo escore de condição corporal no início do tratamento -, os resultados de prenhez à IATF podem ser considerados satisfatórios quando comparados com os dados de prenhez apresentados por Baruselli et al. (2003a); Cutaia et al. (2003a). Esses autores correlacionaram taxas de prenhez à IATF com 
escores de condição corporal em grandes lotes de animais tratados. Os resultados de prenhez se mantiveram semelhantes para os dois tratamentos nos três lotes. As taxas de prenhez em função da classificação ovariana podem ser vistas na Tabela 8.

Tabela 8 - Taxas de prenhez da IATF de vacas Nelore em função da classificação ovariana. Campo Grande, 2004

\begin{tabular}{ll}
\hline Tratamento & Taxa prenhez \\
\hline Ovários A & $50 \%{ }^{\mathrm{ab}}(13 / 26)$ \\
Ovários B & $42,3 \%{ }^{\mathrm{b}}(34 / 79)$ \\
Ovários C & $67,8 \%{ }^{\mathrm{a}}(19 / 28)$ \\
\hline
\end{tabular}

As taxas de prenhez do grupo de animais com ovários A e C não diferiram entre si $(P>0,05)$, o que pode ter sido decorrência do pequeno número de animais avaliados. Entretanto, observaram-se taxas superiores $(P=0,02)$ para animais com classificação de ovário $C$ em relação àqueles classificados como $B$, o que é um resultado interessante, posto que os primeiros têm menor atividade ovariana. Em trabalhos com tratamentos semelhantes, maiores taxas de prenhez para essa classificação ovariana também puderam ser observadas (embora não submetidas à análise estatística), como em Baruselli et al. (2003b) - 50\% vs. 56,5\% para ovários B e C, respectivamente -, ou Cutaia et al. (2003b) - 33,3\% vs. 38,8\% para ovários B e C, respectivamente. Entretanto, em trabalho posterior Cutaia et al. (2003c) não notaram esse efeito $-62,0 \%$ vs. $54,2 \%$ para ovários B e C, respectivamente. Esses dados devem ser melhor estudados em novas investigações, inclusive para se avaliar uma possível interação com outros fatores como escore de condição 
corporal, o que não foi possível avaliar no presente experimento devido ao baixo número de animais avaliados.

Não houve efeito de touro nas taxas de concepção, tanto no lote $2-57,7 \%$ para touro 1 vs. $49,3 \%$ para touro $2(P=0,46)$ - quanto no lote $3-39,6 \%$ para touro 1 vs. $44,4 \%$ para touro $2(P=0,58)$. Fullenwiilder et al. (2001) observaram grande impacto da fertilidade do sêmen sobre as taxas de prenhez à IATF que variaram, no trabalho desses autores, entre 0 e $80 \%$. Já no presente experimento o sêmen utilizado foi previamente avaliado em programa de inseminação convencional na fazenda, o que diminuiu a possibilidade de se utilizar um sêmen com menor fertilidade.

Também não foi observado efeito de seqüência de inseminação sobre as taxas de prenhez dentro dos lotes 2 e 3 ou para o conjunto deles $(P=0,84)$, como pode ser observado na Tabela 9.

Tabela 9 - Taxas de prenhez da IATF de vacas Nelore em função da seqüência de inseminação. Campo Grande, 2004

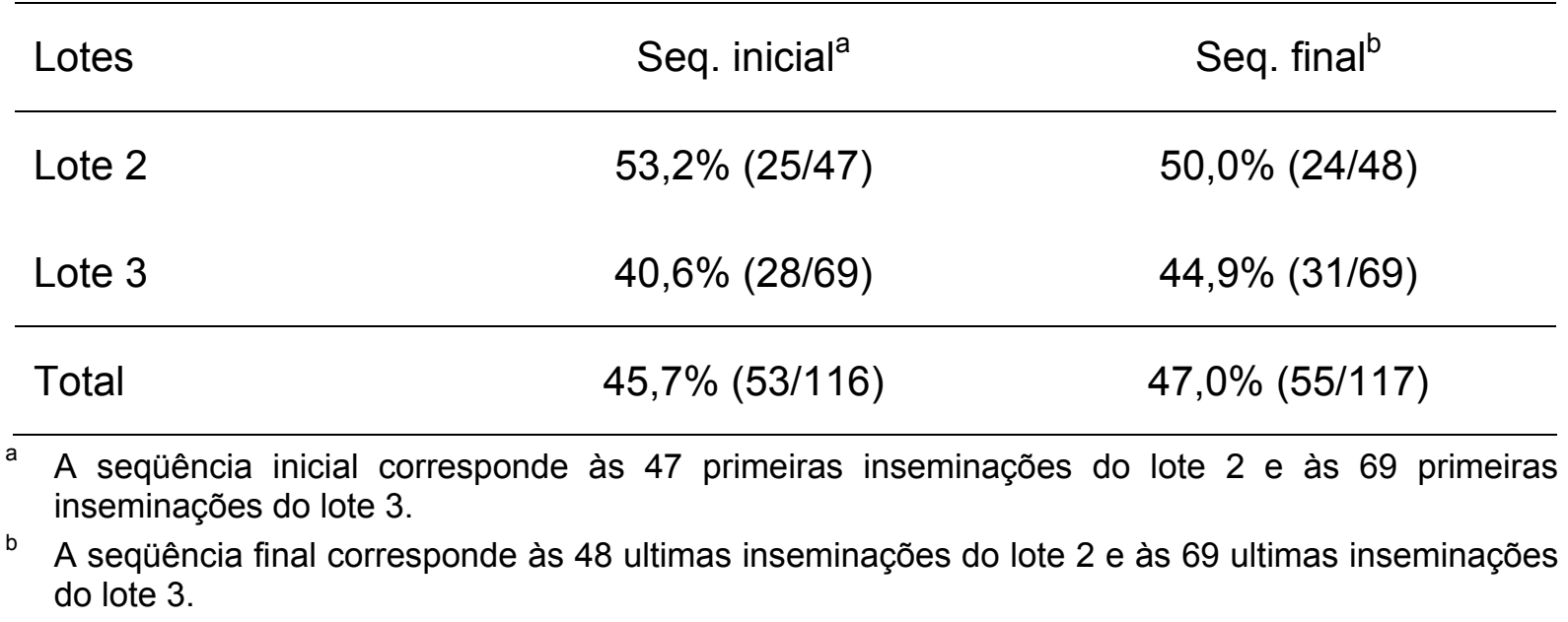

A alteração da fertilidade das primeiras às ultimas inseminações poderia sinalizar um efeito do intervalo entre a indução com o benzoato de estradiol e o 
momento da inseminação, já que o efeito do cansaço do inseminador foi evitado com trocas freqüentes dos profissionais. Isso não foi observado nesta investigação. A presença de muco observável no momento da inseminação não se relacionou com as taxas de prenhez $(P=0,89)$ : animais com muco apresentaram taxa de prenhez de $41,2 \%(7 / 17)$, enquanto que naqueles que não apresentaram muco essa taxa foi de $43 \%(52 / 121)$.

\subsection{IMPLICAÇÕES}

Muitos grupos de pesquisa têm envidado esforços para compreender mais profundamente os vários eventos relacionados ao ciclo estral dos bovinos. Esses estudos foram essenciais para a elaboração de protocolos de IATF como aquele da presente investigação. A IATF tem se mostrado uma ferramenta poderosa na melhoria dos índices reprodutivos de fazendas de gado de corte, tanto pela eliminação das perdas decorrentes de falhas na detecção de cio (CAVALIERI; FITZPATRICK, 1995; STEVENSON et al., 1996) quanto pela antecipação da ciclicidade e da prenhez dos animais tratados, conseqüentes aos efeitos da progesterona (BARUSELLI et al., 2002; VILELA, 2004) e do eCG (BARUSELLI et al. 2003b, c; CUTAIA et al., 2003b, c; MACMILLAN; BURKE, 1996; MACMILLAN; PETERSON, 1993; ROCHE; CROWE; BOLAND., 1992). De posse de protocolos viáveis de IATF, faz-se necessário o estudo de novas técnicas e materiais. objetivando o aumento da eficiência e a diminuição de custos. Apesar de haver, na literatura. muitas informações sobre o uso de protocolos com dispositivos de liberação lenta de progesterona, pouco se encontra especificamente sobre o funcionamento destes. Assim sendo optou-se, nos presentes experimentos, pela 
criação de diferentes dispositivos e pelo estudo da relação entre duas importantes variáveis de construção - superfície de contado e quantidade de progesterona - e os níveis de concentração plasmática de progesterona e os dados de fertilidade à campo. Os resultados aqui obtidos indicam que o dispositivo testado foi eficiente para gerar prenhez em animais em diferentes estágios do ciclo reprodutivo e com diferentes condições de ambiente, à semelhança do dispositivo comercial DIB. Em função dos dados comparativos entre DIB e CIDR, nos quais não se observaram diferenças quanto à eficiência desses produtos (BÓ et al., 2002; MARQUES et al., 2003), pode-se inferir que também não haja diferenças na eficiência entre o dispositivo aqui testado e o CIDR. Por fim, os dados de intervalo tratamento-parto do experimento 3 mostram que, mesmo quando as taxas de prenhez à IATF não são satisfatórias, o tratamento pode ser muito vantajoso, resultando em uma grande antecipação da prenhez - 48 dias no presente experimento. Essa antecipação da prenhez tem um grande impacto econômico. Novas investigações, com diferentes grupos genéticos e em diversas condições de ambiente devem ser realizados, para se verificar de que forma, ou em que intensidade, tais resultados podem ser reproduzidos.

Outro aspecto que também deve ser melhor estudado é a relação entre as concentrações plasmáticas da progesterona liberada pelos dispositivos e o crescimento folicular, a ovulação e a prenhez. Dados da literatura (CUTAIA et al. 2001b) indicam que, em algumas situações, os dispositivos com menor liberação de progesterona - como os dispositivos reutilizados - podem apresentar vantagens sobre aqueles que liberam maior quantidade desse hormônio, aumentando as taxas de prenhez à IATF. Vilela et al. (2003) observaram que, após tratamento com CIDR por sete dias, animais em anestro apresentaram maior crescimento folicular do que 
animais cíclicos, o que pode ser um sinal de que maiores concentrações plasmáticas de progesterona podem influenciar negativamente o crescimento folicular. Por fim, Carvalho (2004) mostrou taxas mais elevadas de crescimento folicular e de ovulação em novilhas que receberam uma dose de PGF $_{2 \alpha}$ no inicio do protocolo de IATF para diminuir as concentrações plasmáticas da progesterona. Esses recentes achados permitem cogitar que os resultados da IATF sejam influenciados por interações entre o padrão de liberação de progesterona pelo dispositivo e outras características dos animais - como ciclicidade, fase reprodutiva, grupo genético etc. Dada a sua importância, esse é um assunto que será tema de novos estudos de forma que, no futuro, seja possível disponibilizar dispositivos de progesterona com diferentes padrões de liberação para garantir o máximo desempenho para cada categoria animal. 


\section{CONCLUSÕES}

\subsection{EXPERIMENTO 1}

Equações de regressão foram estabelecidas como preditoras das concentrações de progesterona em função da dose de progesterona e da área se superfície de contato, tanto para o início quanto para o final do período de inserção. Os altos coeficientes de determinação das equações indicam que estas puderam controlar grande parte da variação da amostra.

\subsection{EXPERIMENTO 2}

Os resultados de concentração plasmática de progesterona no início e no final do período de inserção diferiram entre dispositivos, assim como as quedas diárias de concentração plasmática de progesterona. As equações de regressão estabelecidas no experimento 1 não foram eficientes para estimar as concentrações iniciais e finais de progesterona plasmática dos dispositivos P50-1,0 e P50-1,5.

\subsection{EXPERIMENTOS 3 E 4}

As taxas de concepção à IATF não diferiram entre os dispositivos P50-1,5 e DIB. Os intervalos tratamento-parto dos animais submetidos à IATF foram semelhantes entre P50-1,5 e DIB, porém foram menores do que o intervalo encontrado em animais cobertos por touros. O dispositivo P50-1,5 mostrou ser uma alternativa viável para uso em programas de IATF. 


\section{REFERÊNCIAS ${ }^{1}$}

ADAMS, G. P.; EVANS A. C. O.; RAWLINGS, N. C. Follicular waves and circulating gonadotropins in 8-month-old prepubertal heifers. Journal of Reproduction and Fertility, v. 100, p. 27-33, 1992.

ADAMS, G. P.; KOT, K.; SMITH, C. A.; GINTHER, O. J. Selection of a dominant follicle and suppression of follicular growth in heifers. Animal Reproduction

Science, v. 30, p. 259-271, 1993.

ADAMS, G. P.; MATTERI, R. I.; KASTELIC, J. P., KO, J. C. H.; GINTHER, O. J. Association between surges of follicle-stimulating hormon and the emergence of follicular waves in heifers. Journal of Reproduction and Fertility, v. 94, p. 177-188, 1994.

ALONSO, A.; MAPLETOFT, R. J.; BO, G. A.; TRIBULO, H. E.; CARCEDO, J.; TRIBULO, R.; MENAJOVSKY, J. R. Niveles de hormona luteinizante y de estrógeno en hembras Bos indicus tratadas con prostaglandinas $F_{2} \alpha$. Resultados preliminaries. In: REUNION LATINOAMERICANA DE PRODUCCIÓN ANIMAL, 14., Mar del Plata, 1995. Revista Argentina de Producción Animal, v. 15, p. 961-963, 1995.

ALVAREZ, P.; SPICER, L. J.; CHASE Jr., C. C.; PAYTON, M. E.; HAMILTON, T. D.; STEWART, R. E.; HAMMOND, A. C.; OLSON, T. A.; WETTEMAN, R. P. Ovarian and endocrine characteristics during the estrous cycle in Angus, Brahman and Senepol cows in a subtropical environment. Journal of Animal Science, v. 78, p. 1291-1302, 2000.

ASSOCIAÇÃO BRASILEIRA DE INSEMINAÇÃO ARTIFICIAL. Evolução da inseminação artificial no Brasil (Corte e leite, período de 1999-2003). São Paulo: ASBIA, 2002. Disponível em: <http://www.asbia.org.br/relat03.asp>. Acesso em: 31 jan. 2004.

BAO, B.; GARVERICK, H. A. Expression of steroidogenic enzyme and gonadotropin receptor genes in bovine follicles during ovarian follicular waves: a review. Journal of Animal Science, v. 76, p. 1903-1921, 1998.

Conforme as diretrizes para apresentação de dissertações e teses na Faculdade de Medicina Veterinária e Zootecnia da Universidade de São Paulo. 4. ed. São Paulo: FMVZ-USP. 2003. 84 p. 
BAO, B.; GARVERICK, H. A.;SMITH, G. W.; SMITH, M. F.; SALFEN, B. E.; YOINGQUIST, R. S. Changes in messenger ribonucleic acid ancoding luteinizing hormone receptor, cytochrome P450-side chain cleavage, and aromatase are associated with recruitment and selection of bovine ovarian follicles. Biology of Reproduction, v. 56, p. 1158-1168, 1997.

BARROS, C. M.; FIGUEIREDO, R. A.; PAPA, F. O.; ROCHA, G. Follicular growth in Nelore cows (Bos indicus) after PGF2 administration. Journal of Animal Science, v. 71, p. 216, 1993. Supplement.

BARROS, C. M.; FIGUEIREDO, R. A.; PINHEIRO, O. L. Estro, ovulação e dinâmica folicular em zebuínos. Revista Brasileira de Reprodução Animal, v. 19, p. 9-22, 1995.

BARUSELLI, P. S.; MADUREIRA, E. H.; MARQUE, M. O.; RODRIGUES, C. A.; NASSER, L. F.; SILVA, R. C. P.; REIS, E. L.; SÁ FILHO, M. F. Efeito do tratamento com eCG na taxa de concepção de vacas Nelore com diferentes escores de condição corporal inseminadas em tempo fixo (análise retrospectiva). In: REUNIÃO ANUAL DA SOCIEDADE BRASILEIRA DE TRANSFERÊNCIA DE EMBRIÕES, 2004. Trabalho aceito para apresentação.

BARUSELLI, P. S.; MARQUES, M. O.; CARVALHO, N. A. T.; MADUREIRA, E. H.; CAMPOS FILHO, E. P. Efeito de diferentes protocolos de inseminação artificial em tempo fixo na eficiência reprodutiva de vacas de corte lactentes. Revista Brasileira de Reprodução Animal, v. 26, p. 218-221, 2002.

BARUSELLI, P. S.; MARQUES, M. O.; REIS, E. L.; BÓ, G. A. Tratamientos hormonales para mejorar la performance reproductiva de vacas de cria em anestro em condiciones tropicales. In: SIMPÓSIO INTERNACIONAL DE REPRODUCCION ANIMAL, 5., 2003, Cordoba. Anais... Cordoba, 2003a. p. 103.

BARUSELLI, P. S.; MARQUES, M. O.; NASSER, L. F.; REIS, E. L., BÓ, G. A. Effect of eCG on pregnancy rates of lacting zebu beef cows treated with CIDR-B devices for timed artificial insemination. Theriogenology, v. 59, p. 241, 2003b. Abstract.

BARUSELLI, P. S.; MARQUES, M. O.; REIS, E. L.; MELLO, J. E.; CAMPOS FILHO, E. P. Taxa de concepção de diferentes protocolos de inseminação artificial em tempos fixos em vacas Bos taurus taurus $x$ Bos taurus indicus durante o período pós-parto. In: SIMPÓSIO INTERNACIONAL DE REPRODUCCION ANIMAL, 5., 2003, Cordoba. Anais... Cordoba, 2003c. p. 380.

BASILE, J. R., BENEDITO, V. A. Sincronização do ciclo estral em vacas Nelore com prostaglandina $\mathrm{F}_{2} \alpha$ analoga (cloprostenol) por via intramuscular. Revista Brasileira de Reprodução Animal, v. 3, p. 7-11, 1980. 
BÓ, G .A.; ADAMS, G. P.; CACCIA, M.; MARTINEZ, M.; PIERSON, R. A.; MAPLETOFT, R. J. Ovarian follicular wave emergence after treatment with progestogen and estradiol in cattle. Animal Reproduction Science, v. 39, p. 193204, 1995.

BÓ, G. A Sincronizacion de celos para programas de inseminacion artificial y transferencia de embriones bovinos. In: SIMPOSIO SOBRE CONTROLE FARMACOLÓGICO DO CICLO ESTRAL, FACULDADE DE MEDICINA VETERINÁRIA E ZOOTECNIA, 2000, São Paulo. Anais... São Paulo, 2000. p. 3560.

BÓ, G. A.; ADAMS, G. P.; MAPLETOFT, R. J. Dinámica folicular ovárica en el bovino. In: SIMPOSIO SOBRE CONTROLE FARMACOLÓGICO DO CICLO ESTRAL, FACULDADE DE MEDICINA VETERINÁRIA E ZOOTECNIA, 2000, São Paulo. Anais... São Paulo, 2000. p. 12-34.

BÓ, G. A.; ADAMS, G. P.; NASSER, L. F.; PIERSON, R. A.; MAPLETOFT, R. J. Effect of estradiol valerate on ovarian follicles, emergence of follicular waves and circulating gonadotropins in heifers. Theriogenology, v. 40, p. 225-239, 1993a.

BÓ, G. A.; MARTÍNEZ, M.; NASSER, L. F.; CACCIA, M.; TRIBULO, H.; MAPLETOFT, R. J. Follicular dynamics in Bos indicus and Bos taurus beef cattle under pasture conditions in Argentina. In: CONGRESSO BRASILEIRO DE REPRODUÇÃO ANIMAL, 10., 1993, Campo Grande. Anais... Campo Grande, 1993b. p. 221. Abstract.

BÓ, G. A.; ADAMS, G. P.; PIERSON, R. A.; TRIBULO, H. E.; CACCIA, M.; MAPLETOFT, R. J. Follicular wave dynamics after estradiol-17b treatment of heifers with or without a progesterone implant. Theriogenology, v. 41, p. 1555-69, 1994.

BÓ, G. A.; BARUSELLI, P. S.; MARTÍNEZ, M. F. Pattern and manipulation of follicular development in Bos indicus cattle. Animal Reproduction Science, v. 78, p. 307-326, 2003.

BÓ, G. A.; BARUSELLI, P. S.; MORENO, D.; CUTAIA, L.; CACCIA, M.; TRIBULO, R.; TRIBULO, H.; MAPLETOFT, R. J. The control of follicular wave development for self-appointed embryo transfer programs in cattle. Theriogenology, v. 57, n. 1, p. 52-72, 2002.

CACCIA, M.; BO, G. A. Follicle wave emergence following treatment of CIDR-B implanted beef cows with estradiol benzoate and progesterone. Theriogenology, $\mathrm{v}$. 49, p. 341, 1998. 
CARVALHO, J. B. P. Sincronização da ovulação com dispositivo intravaginal de progesterona (CIDR) em novilhas Bos indicus, Bos indicus x Bos taurus e Bos taurus. 2004. 122 f. Tese (Doutorado em Reprodução Animal). Faculdade de Medicina Veterinária e Zootecnia, Universidade de São Paulo, São Paulo, 2004.

CASTILHO, C., DAYAN, A., BARROS, C. M. Responsiveness of Nelore cows corpus luteum to $\mathrm{PGF}_{2} \alpha$, administered intramusculary or via submucosa vulvar. Arqivos da Faculdade de Veterinária da UFRGS, v. 25, p. 205, 1997. Abstract.

CASTILHO, C.; GAMBINO, L. G.; MOREIRA, M. B. P.; BARROS, C. Desenvolvimento folicular em novilhas girolanda após administração de PGF. Arquivos da Faculdade de Veterinária da UFRGS, v. 24, p. 203, 1996. Abstract.

CAVALIERI, J.; FITZPATRICK, L. A. Oestrus detection techiques and insemination strategies in Bos indicus heiferes synchronised with norgestomet-oestradiol.

Australian Veterinay Journal, v. 72, n. 5, p. 177-82, 1995.

CAVALIERI, J.; RUBIO, I.; KINDER, J. E.; ENTWISTLE, K. W.; FITZPATRICK, L. A. Synchronization of estrus and ovulation and associated endocrine changes in Bos indicus cows. Theriogenology, v. 47, p. 801-814, 1997.

CHENAULT, J. R. Pharmaceutical control of estrous cycles. In: H.H. VAN HORN; WILCOX, C. J. Large dairy herd management. Savoy: American Dairy Science Association, Savoy, 1992. p. 153.

COLAZO, M. G.; BÓ, G. A; ILLUMINATI, H.; MEGLIA, G.; SCHMIDT, E. E.; BARTOLOME, J. Fixed-time artificial insemination in beef cattle using CIDR-B devices, progesterone and estradiol benzoate. Theriogenology, v. 51, p. 404, 1999. Abstract.

COOKE, D. J.; CROWE, M. A.; ROCHE, J. F. Circulating FSH isoform patterns during recurrent increases in fsh through the oestrous cycle of heifers. Journal of Reproduction and Fertility, v. 110, p. 339-345, 1997.

CROWE, M. A.; PADMANABHAN; BEITINS, I. Z., ROCHE,J. F. Esumption of follicular waves in beef cows is not associated with periparturiant changes infolliclestimulating hormone heteronegeity despite major changes in steroid and luteinizing hormone concentrations. Biology of Reproduction, v. 58, p. 1445-1450, 1998.

CUTAIA, L.; MORENO, D.; VILLATA, M. L.; BO, G. A. Synchrony of ovulation in beef caws treated with progesterone vaginal devices and estradiol benzoate administered at device removal or 24 hours later. Theriogenology, v. 55, p. 408, 2001a. Abstract. 
CUTAIA, L.; MORENO, D.; VILLATA, M. L.; BÓ, G. A. Synchrony of ovulation in beef ows treated with progesterone vaginal devices and estradiol benzoate administered at device removal or 24 hours later. Theriogenology, v. 55, p. 408, 2001b.

CUTAIA, L.; VENERANDA, G.; TRÍBULO, R.; BARUSELLI, P. S.; BÓ, G. A. Programas de inseminación artificial a tiempo fijo em rodeos de cría: factores que lo afectan y resultados productivos. In: SIMPOSIO INTERNACIONAL DE REPRODUCCIÓN ANIMAL, 5., 2003, Cordoba. Anais... Córdoba, 2003a.

CUTAIA, L.; TRÍBULO, R.; MORENO,D.; BÓ, G. A. Pregnancy rates in lactating beef cows with progesterone releasing devices, estradiol benzoate and equine chorionic gonadotropin (eCG). Theriogenology, v. 59, p. 216, 2003b. Abstract.

CUTAIA, L.; MORENO, D.; CHESTA, P.; BÓ, G. A. Effecto de la aplicacion de Gonadotrofina Coriôniva Equina (eCG) en dia 6 o en el dia 8 del tratameiento com dispositivos com progesterone en vacas com cria en pobre condição corporal. In: SIMPOSIO INTERNACIONAL DE REPRODUCCIÓN ANIMAL, 5., 2003, Cordoba. Anais... Córdoba, 2003c.

D'OCCHIO, M. J.; NEISH, A.; BROADHURST, L. Differences in gonadotrophin secretion postpartum between Zebu and European breed cattle. Animal Reproduction Science, v. 22, p. 311-317, 1990.

DUFOUR, J. H.; WHITEMORE, H. L.; GINTHER, O. J.; CASIDA, L. E. Identification of the ovulating follicle by its size on different days of the estrous cycle in heifers. Journal Animal Science, v. 34, p. 85-87, 1972.

DUNN, T. G., KALTEMBACH, G. C. Nutrition and the postpartum interval of de ewe, sow and cow. Journal of Animal Science, v. 51, p. 29, 1980.

EVANS, A. C. O.; KOMAR, C. M.; WANDJI, S. A.; FORTUNE, J. E. Changes in androgen secretion and luteinizing hormone pulse amplitude are associated with the recruitment and growth of ovarian follicles during the luteal phase of the bovine estrous cycle. Biology of Reproduction, v. 57, p. 394-401, 1997.

FÊO, J. C. S. A.; BARNABE, R. C. Incidência e fertilidade de cios noturnos em vacas da raça Nelore. Revista Brasileira de Reprodução Animal, v. 4, n. 3-4, p. 25-29, 1980.

FIGUEIREDO, R. A.; BARROS, C. C.; PINHEIRO, O. L.; SOLER, J. M. P. Ovarian follicular dynamics in Nelore Breed (Bos indicus). Theriogenology, v. 47, p. 14891505, 1997. 
FILDS, M. J.; DUBOIS, W.; FIELDS, P. A. Dynamic features of luteal granules ultrastructural changes during the course of pregnancy in the cow. Endocrinology, v. 117, p. $1675-1682,1985$.

FLINT, A. P. F.; SHELDRICK, E. L. Ovarion secretion of oxytocin is stimulated by prostaglandin. Nature, v. 297, p. 587-588, 1982.

FORTUNE, J. E. Ovarian follicular growth and development in mammals. Biology of Reproduction, v. 50, p. 225-232, 1994.

FORTUNE, J. E.; SIROIS, J.; QUIRK, S. M. The growth and differentiation of ovarian follicles during the bovine estrous cycle. Theriogenology, v. 29, p. 95-109, 1988.

FUCHS, A. R.; BEHERENS, O.; HELMER, H.; LIU, C. H.; BARROS, C. M.; FIELDS, M. J. Oxytocin and vasopressin receptors in bovine endometrium and myometrium during the estrous cycle and early pregnancy. Endocrinology, v. 127, p. 629-636, 1990.

FULLENWIILDER, J.; KEMPFER, R.; BARTHLE, C.; LEMASTER, W.; YELICH, J. Use od intravaginal progesterone-releasing device (CIDR) for timed artificial insemination (AI) in crossbreed cattle of Bos indicus breeding. Beef Cattle Report, p. 36-40, 2001.

GALINA, C. S.; ARTUR, G. H. Review on cattle reproduction in the tropics. Part 4. Oestrus cycles. Animal Breed Abstract, v. 58, p. 697-707, 1990.

GAMBINI, A. L. G.; MOREIRA, M. B. P., CASTILHO, C.; BARROS, C. M. Follicular dynamics and synchronization of ovulation in Girolando cows. Biology of Reproduction, v. 56, p. 195, 1997. Abstract.

GINTHER, O. P.; KASTELIC, J. P.; KNOPF, L. Composition and characteristics of follicular waves during the bovine estrous cycle. Animal Reproduction Science, v. 20 , p. $187-200,1989$.

GINTHER, O. P.; KNOPF, L.; KASTELIC, J. P. Temporal associations among ovarian events in cattle during oestrous cycle with two and three follicular waves. Journal of Reproduction and Fertility, v. 87, p.223-230, 1989.

GINTHER, O. P.; KOT, K.; KULICK, L. J.; MARTIN, S. J., WILTBANK, M. C. Relationships between FSH and ovarian follicular waves during the last six months of pregnancy in cattle. Journal of Reproduction and Fertility, v. 108, p. 271-290, 1996a. 
GINTHER, O. P.; WILTBANK, M. C.; FRICKE, P. M.; GIBBONS, J. R.; KOT, K. Selection of the dominant follicle in cattle. Biology of Reproduction, v. 55, p. 11871194, 1996b.

GONG, J. G.; CAMPBELL, B. K.; BRANLEY, T. A.; GUTIERREZ, C. G.; PETERS, A. R.; WEBB, R. Suppression in the secretion of follicle-stimulating hormone and luteinizing hormone, and ovarian follicle development in heifers continuously infused with a gonadotropin-releasing hormone agonist. Biology of Reproduction, v. 55, p. 68-74, 1996.

GOODMAN, A. L.; HODGEN, G. D. The ovarian triad of the primate menstrual cycle. Records Progesterone Hormone Research, v. 39, p. 1-73, 1983.

GOODMAN, A. L.; NIXON, W. E.; JOHNSON, D. K.; HODGEN, G. D. Regulation of folliculogenesis in the cycling rhesus monkey: selection of the dominant follicle.

Endocrinology, v. 100, p. 155-161, 1977.

GORDON, I. Controlled breeding in cattle. Part.1. Hormones in the regulation, oestral control, and set-time artificial insemination. Animal Breed, v. 44, p. 265-275, 1976. Abstract.

HANSEL, W., CONVEY, E. M. Physiology of the estrus cycle. Journal of Animal Science, v. 57, p. 404-24, 1983.

HARDIN, D. R., WARNICK, A. C., FIELDS, M. J. Artificial insemination of subtropical commercial beef cattle following synchronization with cloprostenol. Estrous response. Theriogenology, v. 14, p. 259-68, 1980.

HORTON, E. W.; POYSER, N. L. Uterine luteolytic hormone: a physiological role for prostaglandin $F_{2} \alpha$. Physiology Review, v. 56, p. 595, 1975.

INSKEEP, E. K. Potential uses of prostaglandin in control of reproductive cycles of domestics animals. Journal of Animal Science, v. 36, p. 1149, 1973.

INSTITUTO BRASILEIRO DE GEOGRAFIA E ESTATÍSTICA. Censo brasileiro de rebanhos. São Paulo: IBGE, 2002. Disponível em: <http://www.ibge.gov.br>. Acesso em: 31 jan. 2004.

IRELAND, J. J. Control of follicular growth and development. Journal of Reproduction and Fertility, v. 34, p. 39-54, 1987. 
IRELAND, J. J.; MIHM, M.; AUSTIN, E.; DISKIN, M. G.; ROCHE, J. F. Historical perspective of turnover of dominant follicles during the bovine estrous cycle: key concepts, studies, advancements, and terms. Journal of Dairy Science, v. 83, p. 1846-1658, 2000.

IRELAND, J. L.; GOOD, T. E.; KNIGHT, P. G.; IRELAND, J. J. Alterations in amounts of different forms of inhibin during follicular atresia. Biology of Reproduction, v. 50, p. 1265-1276, 1994.

JOLLY, P. D.; MACDOUGALL, S.; FITZPATRICK, L. A.; MACMILLAN, K. L.; ENTWISTLE, K. W. Physiological effects of undernutrition on postpartum anoestrum in cows. Journal of Reproduction and Fertility, v. 49, p. 477-92, 1995.

KASTELIC, J. P.; GINTHER, O. J. Factors affecting the origin of the ovulatory follicle heifers with induced luteolysis. Animal Reproduction Science, v. 26, p. 13-24, 1991.

KASTELIC, J. P.; KO, J. C. H.; GINTHER, O. P. Suppression of dominant and subordinate ovarian follicles by a protenaeous fraction of follicular fluid in heifers. Theriogenology, v. 34, p. 499-509, 1990.

KASTELIC, J. P.; OLSON, W. O.; MARTINEZ, M.; MAPLETOFT, R. J. Sincronização do estro em bovinos Hereford-Angus com Crestar. Revista Brasileira de Reprodução Animal, v. 21, p. 101-103, 1997.

KESLER, D. J.; FAVERO, R. J. Estrus synchronization in beef females with norgestomet and estradiol valerate. Agri-Practice, v. 17, p. 12-17, 1996.

KESLER, D. J.; FAVERO, R. J.; TROXEL, T. R. Comparison of hydron and silicone implants in the bovine norgestomet and estradiol valerate synchronization procedure. Drug Development Industry Pharmacology, v. 21, p. 475-485, 1995.

KINDER, J. E.; KOJIMA, F. N.; BERGFELD, E. G. M.; WEHRMAN, M. E.; FIKE, K. E. Progestin and estrogen regulation of pulsatile $\mathrm{LH}$ release and development of persistent ovarian follicles in cattle. Journal of Animal Science, v. 74, p. 1424-1440, 1996.

KIRACOFE, G. H., KEAY, L. E., ODDE, K. G. Synchronization of estrus in cyclic beef heifers with prostaglandin analog alfaprostol. Theriogenology, v. 24, p. 737, 1985.

LAMOTHE-ZAVALETA, C.; FREDRIKSSON, G. KINDAHL, H. Reproductive Performance of zebu cattle in Mexico.1. Sexual behaviour and seasonal influence on oestrus cyclicity. Theriogenology, v. 36, p. 887-896, 1991. 
LANDIVAR, C.; GALINA, C. S.; DUCHATEAU, A. Fertility trial in zebu cattle after a natural or controlled estrus with prostaglandin F2 alpha, comparing natural mating with artificial insemination. Theriogenology, v. 23, p. 421-427, 1985.

LARSON, L. L.; BALL, P. J. H. Regulation of estrous cycles in dairy cattle: A review. Theriogenology, v. 38, p. 255-267, 1992.

LAUDERDALE, J. W.; MACALLISTER, J. F.; KRATZER, D. D.; MOODY, E. L. Use of prostaglandin $F_{2} \alpha$ in cattle breeding. Acta Veteninaria Scandinavica, v. 77, p. 181, 1981.

LAVERDIERE, G.; ROY, G. L.; PROULX, J.; LAVOIE, D., DUFOUR, J. J. Estrus synchronization efficiency of $\mathrm{PGF}_{2} \alpha$ injection in Shorthorn-Hereford and crossbred Charolais cattle not having exhibited estrus at 4 or 7 days prior to treatment.

Theriogenology, v. 43, p.899-911, 1995.

LEMASTER, J. W.; YELICH, J. V.; KEMPFER, J. R.; SCHRICK, F. F. Ovulation and estrus characteristics in crossbred Brahman heifers treated with an intravaginal progesterone-releasing insert in combination with prostaglandin $\mathrm{F} 2 \alpha$ and estradiol benzoate. Journal Animal Science, v. 77, p. 1860-1868, 1999.

LOPEZ-BARBELLA, S.; MARTINEZ, L. A.; GAVALDON, L. L. Synchronization of estrous with norgestomet and prostaglandin $\mathrm{F}_{2} \alpha$ in beef cattle. Tropical Animal Production, v. 6, p. 101-104, 1981.

LUCY, M. C.; BILLINGS, H. J.; BUTLER, W. R.; EHNIS, L. R.; FIELDS, M. J.; KESLER, D. J.; KINDER, J. E.; MATTOS, R. C.; SHORT, R. E.; THATCHER, W. W.; WETTEMANN, R. P.; YELICH, J. V.; HAFS, H. D. Efficacy of an intravaginal progesterone insert and an injection of $\mathrm{PGF}_{2} \alpha$ a for synchronizing estrus and shortening the interval to pregnancy in post-partum beef cows,. and peripubertal beef heifers and dairy heifers. Journal of Animal Science, v. 79, p. 982-995, 2001.

LUCY, M. C.; SAVIO, J. D.; BADINGA, L.; DE LA SOTA, R. L.; THATCHER, W. W. Factors that affect ovarian follicular dynamics in cattle. Journal of Animal Science, v. 1992, p. 3615-3626, 1992.

MACMILLAN, K. L., PETERSON, A. J. A new intravaginal progesterone releasing device for cattle (CIDR-B) for estrous synchronization, increasing pregnancy rates and the treatment of post-partum anestrous. Animal Reproduction Science, v. 33, p. 1-25, 1993.

MACMILLAN, K. L., TAUFA, V. K., DAY, A. M. Combination treatments for synchronizing oestrus in dairy heifers. In: CONGRESO BRASILEIRO DE 
REPRODUÇÃO ANIMAL, 11., 1995, Belo Horizonte. Anais... Belo Horizonte: Colégio Brasileiro de Reprodução Animal, 1995. p. 35-45.

MACMILLAN, K. L.; BURKE, C. R. Effects of oestrous cycle control on reproductive efficiency. Animal Reproductive Science, v. 42, p. 307-320, 1996.

MACMILLAN, K. L.; TAUFA, V. K.; BARNES, D. R; DAY, A. M. Plasma progesterone concentrations in heifers and cows treated with a new intravaginal device. Animal Reproduction Science, v. 26, p. 255-240, 1991.

MACMILLAN, K. L.; WASHBURN, S. P.; HENDERSON, H. V.; PETCH, S. F. Effects of varying the progesterone content of CIDR intravaginal devices and multiple CIDR treatments on plasma hormone concentrations and residual hormone content.

Proceedings New Zealand Society of Animal Production, v. 50, p. 471-472, 1990.

MADUREIRA, E. H. Estudo comparativo da sincronização do estro por norgestomet$\mathrm{PGF}_{2} \alpha$ ou syncro-mate $\mathrm{B}$, em gado zebu (Bos indicus) e cacaru $x$ zebu (Bos taurus $\mathrm{x}$ Bos indicus). 135 f. 1995. Tese (Doutorado em Patologia Experimental e Comparada) - Faculdade de Medicina Veterinária e Zootecnia. Universidade de São Paulo, São Paulo, 1995.

MATTON, P.; ADELAKOUN, V.; COUTURE, Y.; DUFOUR, J.J. Growth and replacement of the bovine ovarian follicles during the estrous cycle. Journal of Animal Science, v. 52, p. 813-820, 1981.

MIHM, M.; DISKIN, M. G.; ROCHE, J. F. Regulation of follicular growth in cattle. Reproduction of Domestic Animal, v. 31, n. 3, p. 531-538, 1996.

MILVAE, R. A.; HINCKLEY, S. T.; CARLSON, J. E. Luteotropic and luteolytic mechanisms in the bovine corpus luteum. Theriogenology, v. 45, p. 1327-1343, 1996.

MONNIAUX, D.; HUET, C.; BESNARD, N.; CLÉMENT, F.; BOSC, M.; PISSELET, C.; MONGET, P.; MARIANA, J. C. Follicular grwth and ovarian dynamics in mammals. Journal of Reproduction and Fertility, p. 3-23, 1997a. Suplemento 51.

MONNIAUX, D.; MONGET, P.; BESNARD, N.; HUET, C.; PISSELET, C. Growth factors and antral follicular development in domestic ruminants. Theriogenology, $v$. 47, p. 3-12, $1997 b$.

MORENO, D.; CUTAIA, L.; VILLATA, M. L.; ORTISI, F.; BÓ, G. A. Follicle wave emergente in beef cows treated with progesterone releasing devices, estradiol benzoato and progesterone. Theriogenology, v. 55, p. 408, 2001. Abstract. 
MUNRO, R. K. Concentrations of plasma prpgesterone in cows after treatment with 3 types of progesterone pessaries. Australian Veterinary, v. 64, p. 385-386, 1987.

ODDE, K. G. A review of synchronization of estrus in postpartum cattle. Journal of Animal Science, v. 68, p. 817-830, 1990.

OYEDIPE, E. O., VOH, A. A., MARIRE, B. N. Plasma progesterone concentrations during the oestrus cycle and following fertile and non-fertile inseminations of zebu heifers. British Veterinary Journal, v. 142, p. 41-46, 1986.

PETERSON, A. J.; HENDERSON, H.C. Plasma progesterone concentrations in ovariectomized dairy cows treated with a CIDR-B breeding device. Journal of Reproduction and Fertility, v. 43, p. 315, 1990. Supplement.

PIERSON, R. A.; GINTHER, O. J. Follicular populations during the estrous cycle in heifers I. Influence of day. Animal Reproduction Science, v. 14, p.165-176, 1987a.

PIERSON, R. A.; GINTHER, O. J. Follicular populations during the estrous cycle in heifers II. Influence of right and left sides and intraovarian effect of the corpus luteum. Animal Reproduction Science, v. 14, p. 177-186, 1987b.

PIERSON, R. A.; GINTHER, O. J. Ultrassonic imaging of the ovaries and uterus in cattle. Theriogenology, v. 29, p. 21-37, 1988.

PIERSON. R. A.; GINTHER, O. J. Ultrassonography of the bovine ovary. Theriogenology, v. 21, p. 495-504, 1984.

PINHEIRO, O. L.; BARROS, C. M., FIGUEREDO, R. A., VALLE, E. R.; ENCARNAÇÃO, R. O.; PADOVANI, C. R. Estrous behavior and the estrus-toovulation interval in Nelore cattle (Bos indicus) with natural estrus or estrus induced with prostaglandin F2alpha or norgestomet and estradiol valerate. Theriogenology, v. 49 , p. $667-681,1998$.

PRICE, C. A. The control of FSH secretion in the larger domestic species. Journal of Endocrinology, v. 131, p. 177-184, 1991.

RAHE, C. H.; OWENS, R. E.; FLEEGER, J. L.; NEWTON, H. J.; HARMS, P. G. Pattern of plasma luteinizing hormone in the cyclic cow: dependence upon the period of the cycle. Endocrinology, v. 107, p. 498-503, 1980. 
RAJAKOSK, E. The ovarian follicular system in sexually mature heifers with special reference to seasonal, cyclical, and left-right variations. Acta Endocrinology, v. 34, p. 7-68, 1960.

RANDEL, R. D. LH and ovulation in Brahman $x$ Hereford and Hereford heifers. Journal of Animal Science, v. 43, p. 300, 1976.

RANDEL, R. D. Seasonal effects on female reproductive functions in the bovine (Indian breeds). Theriogenology, v. 21, p. 170-185, 1984.

RATHBONE, M. J.; MACMILLAN, K. L.; INSKEEP, K.; BURGGRAAF, S.; BUNT, C. R. Fertility regulation in cattel. Journal of Controlled Release, v. 54, p. 117-148, 1998.

RHODES III, R. C.; RANDEL, R. D.; HARMS, P. G. Reproductive estudies of Brahman cattle IV. Luteinizing hormones levels in ovariectomized Brahman, Brahman $x$ Hereford and Hereford cows following a $20 \mathrm{mg}$ dose of oestradil-17 $\beta$. Theriogenology, v. 10, p. 429-437, 1978.

RHODES, F. M.; DEATH, G.; ENTWISTLE, K. M. Animal and temporal effects on ovarian follicular dynamics in Brahman heifers. Animal Reproduction Science, $v$. 38, p. 265-277, 1995.

ROBERSON, M. S.; WOLFE, M. W.; STUMPF, T. T.; KITTOK, R. J.; KINDER, J. E. Luteinizing hormone secretion and corpus luteum function in cows receiving two levels of progesterone. Biology of Reproduction, v. 41, p. 997-1003, 1989.

ROCHE, J. F.; CROWE, M. A.; BOLAND, M. P. Postpartum anestrus in dairy and beef cows. Animal Reproduction Science, v. 28, p. 371-378, 1992.

ROWSON, L. E. A.; TERVIT, R.; BRAND, A. The use of prostaglandin for synchronization of estrus in cattle. Journal of Reproduction and Fertility, v. 29, p. 145, 1972.

SAVIO, J. D.; KEENAN, L.; BOLAND, M. P.; ROCHE, J. F. Pattern of growth of dominant follicles during the oestrous cycle in heifers. Journal of Reproduction and Fertility, v. 83, p. 663-671, 1988.

SAVIO, J. D.; THATCHER, W. W.; BADINGA, L.; DE LA SOTA, R. R.; WOLFENSON, D. Regulation of dominant follicle turnover during the oestrous cycle in cows. Journal of Reproduction and Fertility, v. 97, p. 197-203, 1993. 
SCHMITT, E. J. P.; DIAZ, T. C.; DROST, M.; ROOMES, C.; THATCHER, W. W. Use of a $\mathrm{GnRH}$ agonist on human chorionic gonadotropin for timed insemination in cattle. Journal of Animal Science, v. 74, p. 1084-1091, 1996.

SEGERSON, E. C.; HANSEN, T. R.; LIBBY, D. W.; RANDEL, R. D., GETZ, W. R. Ovarian and uterine morphology and function in Angus and Brahman cows. Journal of Animal Science, v. 59, p. 1026-1046, 1984.

SIROIS, J.; FORTUNE, E. Lengthening the bovine estrous cycle with low levels of exogenous progesterone: a model for studing ovarian follicular dominance.

Endocrinology, v. 127, p. 916, 1990.

SIROIS, J.; FORTUNE, E. Ovarian follicular dynamics during the estrous cycle in heifers monitored by real-time ultrasonography. Biology of Reproduction, v. 39, p. 308-317, 1988.

SMITH, R. D., POMERANZ, A. J., BEAL, W. E., MCCANN, J. P., PILBEAM, T. E., HANSEL, W. Insemination of Hostein heifers at a preset time after estrus cycle synchronization using progesterone and prostaglandin. Journal of Animal Science, v. 58, p. 792, 1984.

STEVENSON, J. S.; SMITH, M. W.; JAEGER, J. R.; CORAH, L. R.; LeFEVER, D. G. Detection of estrus by visual observation and radiotelemetry in peripuberal, estrussyncronized beef heifers. Journal of Animal Science, v. 74, p. 729-735, 1996.

STOCK, J.; FORTUNE J. E. Ovarian follicular dominance in cattle: relationship between prolonged growth of the ovulatory follicle and endocrine parameters. Endocrinology, v. 132, p. 1108-1116, 1993.

SUNDERLAND, S. J.; CROWE, M. A.; BOLAND, M. P.; ROCHE, J. F., IRELAND, J. $\mathrm{J}$. Selection, dominance and atresia of follicles during the oestrous cycle of heifers. Journal of Reproduction and Fertility, v. 101, p. 547-555, 1994.

TANABE, T. Y.; HANN, R. C. Synchronized estrus and subsequent conception in dairy heifers treated with prostaglandin $\mathrm{F}_{2} \alpha$. I. Influence of stage of cycle at treatment.

Journal Dairy Science, v. 58, p. 805-811, 1984.

TAYLOR, C.; RAJAMAHENDRAM, R. Follicular dynamics and hábeas luteum growth and function in pregnant versus nonpregnant dairy cows. Journal of Dairy Science, v. 74 , p. 115-123, 1991. 
THATCHER, W. W.; CHENAULT, J. R. Reproductive physiological responses of cattle to exogenous prostaglandin $F_{2} \alpha$. Journal of Dairy Science, v. 59, p. 13661375, 1976.

THATCHER, W. W.; GUZELOGLU, A.; MATTOS, R. R.; BINELLI, M.; HANSEN, T. $\mathrm{R}$.; PRU, J. K. Uterine-conceptus interactions and reproductive failure in cattle. Theriogenology, v. 56, p. 1435-1450, 2001.

TRIBULO, H. E.; GO, G. A.; KASTELIC, J. P.; PAWLYSHYN, V.; BARTH, A. D.; MAPLETOFT, R. J. Estrus synchronization in cattle with estradiol-17 $\beta$ and CIDR-B vaginal devices. Theriogenology, v. 43; p. 340, 1995. Abstract.

TURZILLO, A. M.; FORTUNE, J. E. Supression of the secondary FSH surge with bovine follicular fluid is associated with delayed ovarian follicular development in heifers. Journal of Reproduction and Fertility, v. 89, p. 643-653, 1990.

UEHLINGER, H,; BINDER, H.; HAUSER, B. RÜSH, P.; ZEROBIN, K. Hormonanalytischer vergleich der vaginaleinlagen CIDR und PRID bei ovariektomierten kühen. Schwiz. Arch. Tierheilk, v. 137, p. 81-86, 1995.

VILELA, E. E. Utilização de dispositivo de liberação intravaginal de progesterona no protocolo de sincronização $\left(\mathrm{GnRH} / \mathrm{PGF}_{2} \alpha / \mathrm{GnRH}\right)$ associado à remoção temporária de bezerros em vacas Nelore paridas. 2004. $58 \mathrm{f}$.

Dissertação (Mestrado.Nutrição e Produção Animal). Faculdade de Medicina Veterinária e Zootecnia, Universidade Estadual "Júlio de Mesquita Filho", Botucatu, 2004.

VILELA, E. E.; VASCONCELOS, J. L. M.; SANTOS, R. M.; PEREZ, G. C.; LOSI, T. C; MARQUEZINI, G. H. L. Efeito da duração do implante de progesterona e da remoção do bezerro no diâmetro folicular em vacas Nelore pós-parto. Revista Brasileira de Reprodução Animal, v. 27, n. 3, p. 421-423, 2003.

VISCARRA, J. A.; WETERMANN, R. P.; SPITZER, J. C.; MORRISON, D. G. Body condition at parturition and postpartum weight gain inflence luteal activity and concentrations of glucose, insulin andnonesterified fatty acids in plasma of primiparous beef cows. Journal of Animal Science, v. 76, p. 493-500, 1998.

VOSS, A. K.; FORTUNE, J. E. Levels of mensenger ribonucleic acid for cholesteron side-chain cleavage cytocrome P450 and 3b-hidroxysteroide dehydrogenase in bovine preovulatory follicles after the LH surge. Endocrinology, v. 132, p. 888-894, 1993a. 
VOSS, A. K.; FORTUNE, J. E. Levels of mensenger ribonucleic acid for cytocrome P450 and 17b-hydroxylase and P450 aromatase in bovine preovulatory follicles after the LH surge. Endocrinology, v. 132, p. 2239-2245, 1993b

WATHES, D. C.; ROBINSON, R. S.; MANN, G. E.; LAMMING, G. E. The establishment of early pregnancy in cows. Reproduction Domestic Animals, v. 33, p. 279-84, 1998.

WHITTAKER, P. R.; COLAZO, M. G.; MARTINEZ, M. F.; KASTELIC, J. P.; MAPLETOFT, R. J. New or used CIDER-B devices and estradiol benzoato, with or without progesterone, for fixed-time Al in beef cattle. Theriogenology, v. 57, p. 391, 2002. Abstract.

WILMUT, I.; MOLLER, A. N. Sperm transport into the oviducts of heifers mated early in estros. Reproduction Nutrition Development, v. 24, p. 261, 1984.

WILTBANK, J. N.; GONZALEZ-PADILLA, E. Synchronization and induction of estrus in heifers with a progestagen and estrogen. Ann. Biol. Animal Biochim. Biophys, v. 15, p. 255, 1975.

WILTBANK, J. N.; ZIMMERMAN, D. R.; INGALLS, J.E.; ROWDEN, W. W. Use of progestational compounds alone or in combinations with estrogen for synchronization of estrus. Journal of Animal Science, v. 20, p. 990-994, 1965.

WILTBANK, M. C. Nuevos conceptos sobre los efectos de la nutrición en la reproducción. In: SIMPOSIO INTERNACIONAL DE REPRODUCTION ANIMAL, 5., 2003, Cordoba. Anais... Cordoba, 2003. p.150-145.

WILTBANK, M. C.; PURSLEY, J. R.; FRICKE, P. M.; VASCONCELOS, J.; GUENTHER, J. N.; GIBBONS, J. R.; GINTHER, O. J. Development of Al and ET programs that do not require detection of estrus using recent information on follicular growth. In: ANNUAL CONVENTION PORTLAND, 15., 1996, Oregon.

Proceedings... Oregon: American Embryo Transfer Association, 1996. p. 23-44.

WINKLER, V. W.; BRORODKIN, S.; WEBEL, S. K.; MANNEBACH, J. T. In vitro and in vivo considerations of a novel matrix-controlled bovine progesterone-releasing intravaginal device. Journal of Pharmacy Science, v. 66, p. 816-818, 1977.

WISHART, D. F. Observations on the oestrous cycle of the Friesian heifers. Veterinary Records, v. 90, p. 595-597, 1972.

WISHART, D. F., YOUNG, I. M. Artificial insemination of progestin (sc21009) treated cattle at predetermined times. Veterinary Records, v. 45, p. 503, 1974. 
YAVAS, Y.; JOHSON, W. H.; WALTON, J. S. Modification of follicular dynamics by exigenous $\mathrm{FSH}$ and progesterone and the induction of ovulation using hCG in postpartum beef cows. Theriogenology, v. 52, p. 949-963, 1999.

YELICH, V. A vaginal insert (CIDR) to synchronize estrus and time-AI. In: FIELDS, M. J.; SANDS, R. S.; YELICH, J. V. (eds.). Factors affecting calf crop:

biotechnology of reproduction. Boca Raton: CRC Press, 2002. p. 87-100. 